\title{
Canopy position has a profound effect on soybean seed composition
}

\author{
Steven C Huber ${ }^{1,2,3}$ ， Kunzhi Li ${ }^{1,2,4}$ ， Randall Nelson ${ }^{1,3}$ ， Alexander Ulanov ${ }^{5}$ ， Catherine M DeMuro $^{1}$, Ivan \\ Baxter Corresp. 6, 7 \\ ${ }^{1}$ Global Change and Photosynthesis Research Unit, United States Department of Agriculture, Agricultural Research Service, Urbana, IL, United States \\ 2 Department of Plant Biology, University of Illinois at Urbana-Champaign, Urbana, IL, United States \\ 3 Department of Crop Sciences, University of Illinois at Urbana-Champaign, Urbana, Illinois, United States \\ 4 Lab of plant nutrition genetic engineering, Kunming University of Science and Technology, Kunming, Yunnan, China \\ 5 Metabolomics Facility, Carver Biotechnology Center, University of Illinois at Urbana-Champaign, Urbana, Illinois, United States \\ 6 Plant Genetics Research Unit, United States Department of Agriculture Agricultural Research Service, St. Louis, Missouri, United States \\ 7 Donald Danforth Plant Science Center, Creve Coeur, Missouri, United States \\ Corresponding Author: Ivan Baxter \\ Email address: ivan.baxter@ars.usda.gov
}

Although soybean seeds appear homogeneous, their composition (protein, oil and mineral concentrations) can vary significantly with the canopy position where they were produced. In studies with 10 cultivars grown over a 3-yr period, we found that seeds produced at the top of the canopy have higher concentrations of protein but less oil and lower concentrations of minerals such as $\mathrm{Mg}, \mathrm{Fe}$, and Cu compared to seeds produced at the bottom of the canopy. Among cultivars, mean protein concentration (average of different positions) correlated positively with mean concentrations of $\mathrm{S}, \mathrm{Zn}$ and $\mathrm{Fe}$, but not other minerals. Therefore, on a whole plant basis, the uptake and allocation of S, Zn and Fe to seeds correlated with the production and allocation of reduced $\mathrm{N}$ to seed protein; however, the reduced $\mathrm{N}$ and correlated minerals ( $\mathrm{S}, \mathrm{Zn}$ and Fe) showed different patterns of allocation among node positions. For example, while mean concentrations of protein and Fe correlated positively, the two parameters correlated negatively in terms of variation with canopy position. Altering the microenvironment within the soybean canopy by removing neighboring plants at flowering increased protein concentration in particular at lower node positions and thus altered the node-position gradient in protein (and oil) without altering the distribution of $\mathrm{Mg}$, $\mathrm{Fe}$ and $\mathrm{Cu}$, suggesting different underlying control mechanisms. Metabolomic analysis of developing seeds at different positions in the canopy suggests that availability of free asparagine may be a positive determinant of storage protein accumulation in seeds and may explain the increased protein accumulation in seeds produced at the top of the canopy. Our results establish nodeposition variation in seed constituents and provide a new experimental system to identify genes controlling key aspects of seed composition. In addition, our results provide an 
unexpected and simple approach to link agronomic practices to improve human nutrition and health in developing countries because food products produced from seeds at the bottom of the canopy contained higher Fe concentrations than products from the top of the canopy. Therefore, using seeds produced in the lower canopy for production of ironrich soy foods for human consumption could be important when plants are the major source of protein and human diets can be chronically deficient in Fe and other minerals. 


\section{Canopy position has a profound effect on soybean seed composition}

2

3 Steven C Huber ${ }^{1,2,3 \wedge *}$, Kunzhi Li ${ }^{1,2,4, \wedge}$, Randall Nelson ${ }^{1,3 \wedge}$, Alexander Ulanov ${ }^{5}$, Catherine M.

4

5

6

7

9

10

11

12

13

14

15

16

17

18

19

20

21

22

23

24

25

26

DeMuro $^{1}$, and Ivan Baxter ${ }^{6,7 *}$

1 Global Change and Photosynthesis Research Unit, United States Department of Agriculture, Agricultural Research Service, Urbana, IL, United States

2 Department of Plant Biology, University of Illinois at Urbana-Champaign, Urbana, IL, United States 3 Department of Crop Sciences, University of Illinois at Urbana-Champaign, Urbana, Illinois, United States

4 Lab of plant nutrition genetic engineering, Kunming University of Science and Technology, Kunming, Yunnan, China

5 Metabolomics Facility, Carver Biotechnology Center, University of Illinois at Urbana-Champaign, Urbana, Illinois, United States

6 Plant Genetics Research Unit, United States Department of Agriculture Agricultural Research Service, St. Louis, Missouri, United States

7 Donald Danforth Plant Science Center, Creve Coeur, Missouri, United States

${ }^{\wedge}$ These authors contributed equally to this work

*Correspondence: ivan.baxter@ars.usda.gov or steven.huber@ars.usda.gov 
27 Abstract

Although soybean seeds appear homogeneous, their composition (protein, oil and mineral concentrations) can vary significantly with the canopy position where they were produced. In studies with 10 cultivars grown over a 3-yr period, we found that seeds produced at the top of the canopy have higher concentrations of protein but less oil and lower concentrations of minerals such as $\mathrm{Mg}, \mathrm{Fe}$, and $\mathrm{Cu}$ compared to seeds produced at the bottom of the canopy. Among cultivars, mean protein concentration (average of different positions) correlated positively with mean concentrations of $\mathrm{S}, \mathrm{Zn}$ and Fe, but not other minerals. Therefore, on a whole plant basis, the uptake and allocation of $\mathrm{S}, \mathrm{Zn}$ and Fe to seeds correlated with the production and allocation of reduced $\mathrm{N}$ to seed protein; however, the reduced $\mathrm{N}$ and correlated minerals $(\mathrm{S}, \mathrm{Zn}$ and $\mathrm{Fe}$ ) showed different patterns of allocation among node positions. For example, while mean concentrations of protein and Fe correlated positively, the two parameters correlated negatively in terms of variation with canopy position. Altering the microenvironment within the soybean canopy by removing neighboring plants at flowering increased protein concentration in particular at lower node positions and thus altered the node-position gradient in protein (and oil) without altering the distribution of $\mathrm{Mg}, \mathrm{Fe}$ and $\mathrm{Cu}$, suggesting different underlying control mechanisms. Metabolomic analysis of developing seeds at different positions in the canopy suggests that availability of free asparagine may be a positive determinant of storage protein accumulation in seeds and may explain the increased protein accumulation in seeds produced at the top of the canopy. Our results establish node-position variation in seed constituents and provide a new experimental system to identify genes controlling key aspects of seed composition. In addition, our results provide an unexpected and simple approach to link agronomic practices to improve human nutrition and health in developing countries because food products produced from seeds at the bottom of the canopy contained higher Fe concentrations than products from the top of the canopy. Therefore, using seeds produced in the lower canopy for production of iron-rich soy foods for human consumption could be important when plants are the major source of protein and human diets can be chronically deficient in Fe and other minerals. 


\section{Introduction}

58

59

60

Although soybean seeds from a given plant may appear physically homogeneous, it has long been known that seed produced at the top of the canopy can have higher protein and less oil compared to seeds from the bottom of the canopy (Collins \& Cartter 1956). Subsequently it was demonstrated that positional effects are observed with determinate as well as indeterminate soybeans (Escalante \& Wilcox 1993a) and in normal protein as well as high-protein breeding lines (Escalante \& Wilcox 1993b). While these effects on protein and oil concentrations have been documented to occur, they are nonetheless not widely recognized today and there are no insights concerning possible physiological mechanisms that may underlie these positional effects. There are many other important seed constituents, in particular minerals, but the impact of canopy position on many of these seed constituents is unknown. Because legumes like soybean can contribute not only protein to the human diet but also minerals like iron $(\mathrm{Fe})$ and zinc $(\mathrm{Zn})$, canopy position effects on the concentrations of essential minerals could be important, especially for the health and nutrition of children and women. According to the World Health Organization, Fe deficiency is currently the most widespread mineral deficiency affecting more than $30 \%$ of the world's population (http://www.who.int/nutrition/topics/ida/en/). One approach to control this problem is to increase Fe intake via dietary diversification with Fe-rich foods and it is possible that variation with canopy position could be exploited.

Several factors could affect the development of seeds at the top of the plant differently than those at the bottom of the canopy and therefore could be responsible for differences in seed composition at maturity. First, flowering in the indeterminate soybean plants as used in the present study occurs first at lower nodes; thus, there is the potential for seeds lower in the canopy to develop over a longer period. However, while there is a lot of information about node position and flowering, there are few reports that have documented differences in duration of the seed fill period (SFP) as a function of node, as was demonstrated in cultivar 'Williams79' (Raboy \& Dickinson 1987). A second factor is that seeds lower in the canopy also develop under altered environmental conditions in terms of temperature, irradiance, light quality and humidity, which are recognized to impact soybean seed composition (Carrera et al. 2009; Carrera et al. 2011; Wolf et al. 1982). A third factor is the contribution of remobilization of reserves, including minerals, from leaves that may vary among minerals and with node position. 
87 Therefore, the role of canopy microenvironment and node position on seed composition warrants further consideration.

In the present study, we grew a core group of ten soybean lines in Urbana, IL, over a 3yr period and monitored seed composition (protein, oil and mineral element concentration) at maturity as a function of node position. In general, there was a continuum in composition with seed that developed at the top of the canopy having more protein but less oil and reduced concentrations of minerals such as $\mathrm{Mg}, \mathrm{Fe}$, and $\mathrm{Cu}$ compared to seeds produced at the bottom of the canopy. Of particular note was the variation in Fe concentration, which was generally $\sim 20 \%$ higher in seeds from the bottom of the canopy. The differences in mineral concentrations such as Fe could have direct impact on use of soybeans for human food in countries that primarily depend on plant protein sources for intake of minerals. We also tested several possible developmental and micro-environmental factors for their ability to influence the seed compositional gradients, and used metabolomic profiling of developing seeds to investigate biochemical determinants of the protein and oil gradients. Collectively, the results establish a new type of seed heteromorphism in soybean where seeds appear physically homogenous but differ in composition and provide new insights to some of the underlying factors that may be responsible for the gradients in composition from bottom to top of the canopy.

\section{Materials and Methods}

\section{Plant growth and sampling}

Soybean lines were grown at the University of Illinois South Farm, Urbana, IL, in a randomized complete block design with three replicates each year. Each plot consisted of three rows $2.5 \mathrm{~m}$ long, with $0.75 \mathrm{~m}$ between rows and a planting density of roughly $30 \mathrm{seeds} \mathrm{m}^{-1}$. To produce the thinning treatment, all but three plants were removed from each row shortly after flowering. Delaying thinning until after the reproductive period had begun minimized branching on the remaining plants. Approximately $20 \mathrm{~cm}$ of plants were thinned from the ends of each row and the third plant was left in the middle in the row. The remaining plants were spaced approximately $1 \mathrm{~m}$ apart.

Plants were harvested at maturity. All plants were cut close to ground level and brought into the laboratory. Each stem was divided into four quadrants and the stem fractions in each quadrant were threshed together for each plot. Only normal-sized plants were included in the 
118 analysis, and extremely small, wrinkled or off-color seeds were manually removed from all

119 samples before analysis.

\section{Soy products}

122 To produce flour, soybeans were blanched (boiled for $\sim 25$ minutes) and then baked

123 before grinding. To produce soymilk and okara (remaining solids), soybeans were blanched

124 (boiled for $\sim 5 \mathrm{~min}$ ) twice and then ground in water and cooled slightly. The soymilk (liquid

125 phase) and okara (solid phase) were separated using a cheesecloth and then dried separately and

126 reground before analysis.

\section{Seed storage product analysis}

Protein and oil were measured with an Infratech 1241 Grain Analyzer (FOSS Analytical

AB, Höganäs, Sweden), which is a true Near Infrared Transmission instrument that generates a spectrum from 850 to $1050 \mathrm{~nm}$ via the monochrome light source and mobile grating system. A $50-\mathrm{ml}$ seed sample was used that allowed for 10 subsample readings reported on a $13 \%$ moisture basis.

\section{Ionomic analysis}

Seed analysis was conducted as described in Ziegler et al. 2012. Briefly, single seeds concentrated nitric acid before loading onto an Elan ICP-MS. Internal standards were used to control for differences in dilution and sample injection. Leaf and soy products were analyzed in the same manner except that samples were added to digestion tubes by hand and weighed. Custom scripts were used to correct for internal standards and correct for sample weight.

\section{Metabolomic analysis}

Metabolome analysis was done through Metabolomics Center, Roy J. Carver Biotechnology Center, University of Illinois at Urbana-Champaign. Frozen seeds of the cultivar

'Williams 82' with attached seed coats were homogenized in liquid nitrogen and about $25 \mathrm{mg}$ FW was extracted at room temperature with $1 \mathrm{~mL}$ of $50 \%$ methanol followed by addition of 800 $\mu 1$ of methanol:chloroform (1:2) as outlined in Supplemental File 7. Each extraction was followed by centrifugation ( $5 \mathrm{~min}$ at $15,000 \mathrm{~g}$ ), and the supernatants were collected. With the 
149 exception of samples for analysis of coenzymes, final extracts were evaporated under vacuum at $150-60{ }^{\circ} \mathrm{C}$ and subjected to $\mathrm{GC} / \mathrm{MS}$ analysis.

151

152 Metabolic profiling: Dried extracts were derivatized with $100 \mu \mathrm{L}$ methoxyamine hydrochloride

153 (40 mg ml $\mathrm{m}^{-1}$ in pyridine) for $90 \mathrm{~min}$ at $50{ }^{\circ} \mathrm{C}$, then with $100 \mu \mathrm{L}$ MSTFA at $50{ }^{\circ} \mathrm{C}$ for $120 \mathrm{~min}$, and 154 following 2-hour incubation at room temperature. $5 \mu \mathrm{L}$ of the internal standard (hentriacontanoic 155 acid, $10 \mathrm{mg} \mathrm{ml}^{-1}$ ) was added to each sample prior to derivatization. Metabolites were analyzed 156 using a GC-MS system (Agilent Inc, CA, USA) consisting of an Agilent 7890 gas 157 chromatograph, an Agilent 5975 mass selective detector and a HP 7683B autosampler. Gas 158 chromatography was performed on a ZB-5MS $(60 \mathrm{~m} \times 0.32 \mathrm{~mm}$ I.D. and $0.25 \mu \mathrm{m}$ film thickness $)$ 159 capillary column (Phenomenex, CA, USA). The inlet and MS interface temperatures were 250 $160{ }^{\circ} \mathrm{C}$, and the ion source temperature was adjusted to $230{ }^{\circ} \mathrm{C}$. An aliquot of $1 \mu \mathrm{L}$ was injected with 161 the split ratio of 10:1. The helium carrier gas was kept at a constant flow rate of $2 \mathrm{ml} \mathrm{min}^{-1}$. The 162 temperature program was: 5-min isothermal heating at $70^{\circ} \mathrm{C}$, followed by an oven temperature 163 increase of $5{ }^{\circ} \mathrm{C} \mathrm{min}$ m $^{-1}$ to $310^{\circ} \mathrm{C}$ and a final $10 \mathrm{~min}$ at $310^{\circ} \mathrm{C}$. The mass spectrometer was 164 operated in positive electron impact mode (EI) at $69.9 \mathrm{eV}$ ionization energy at m/z 30-800 scan 165 range.

166

Amino acid analysis: A $20 \mu \mathrm{l}$ aliquot of the internal standard DL-chlorophenylalanine (1 $\mathrm{mg} \mathrm{ml}^{-}$ 168 ${ }^{1}$ in $0.1 \mathrm{M} \mathrm{HCI}$ ) was added to the extracts, dried under vacuum, derivatized with $50 \mu 1$ of neat NMethyl-N-tert-butyldimethylsilyltrifluoroacetamide (MTBSTFA), and $50 \mu \mathrm{L}$ of acetonitrile at 80 ${ }^{0} \mathrm{C}$ for $4 \mathrm{~h}$, cooled to room temperature and centrifuged briefly to remove condensate from the top of tube prior to injection of $1 \mu \mathrm{L}$ at 5:1 split ratio into the GC/MS system, which consisted of an Agilent 6890N (Agilent Inc, Palo Alto, CA, USA) gas chromatograph, an Agilent 5973 mass selective detector and Agilent 7683B autosampler. Gas chromatography was performed on a 60 $\mathrm{m}$ ZB-5MS column with $0.32 \mathrm{~mm}$ inner diameter (I.D.) and $0.25 \mu \mathrm{m}$ film thickness

175 (Phenomenex, CA, USA) with injection temperature and MSD transfer line of $230{ }^{\circ} \mathrm{C}$ both, and 176 the ion source adjusted to $230^{\circ} \mathrm{C}$. The helium carrier gas was set at a constant flow rate of $2 \mathrm{ml}$ $177 \mathrm{~min}^{-1}$. The temperature program was $5 \mathrm{~min}$ at $150{ }^{\circ} \mathrm{C}$, followed by an oven temperature ramp of 5 $178{ }^{\circ} \mathrm{C} \mathrm{min}-1$ to $315^{\circ} \mathrm{C}$ for a final $3 \mathrm{~min}$. The mass spectrometer was operated in positive electron 179 impact mode (EI) at $69.9 \mathrm{eV}$ ionization energy in m/z 50-800 scan range. Acquired data were 
180

181

182

183

184

185

186

187

188

189

190

191

192

193

194

195

196

197

198

199

200

201

202

203

204

205

206

207

208

209

210

normalized to the internal standard (DL-p-Chlorophenylalanine) and sample fresh weight. Amino acid concentrations were calculated based on 2 to $75 \mu \mathrm{g} \mathrm{ml}^{-1}$ standard curves.

Free fatty acids, total fatty acids and coenzymes were also measured and values obtained used in the global analysis, but specific results are not presented. Detailed methods for the analysis are available on request.

The spectra of all chromatogram peaks were compared with electron impact mass spectrum libraries NIST08 (NIST, MD, USA), W8N08 (Palisade Corporation, NY, USA), and a custombuilt database (460 unique metabolites). All known artificial peaks were identified and removed. To allow comparison between samples, all data were normalized to the corresponding internal standard and the sample fresh weight (FW). The spectra of all chromatogram peaks were evaluated using the AMDIS 2.71 (NIST, MD, USA) program. Metabolite concentrations were reported as concentrations relative to the internal standard (i.e., target compound peak area divided by peak area of internal standard: $\mathrm{N}_{\mathrm{I}}=\mathrm{X}_{\mathrm{i}} \times \mathrm{X}^{-1}$ IS) per gram sample weight. The instrument variability was within the standard acceptance limit (5\%).

Metabolites with more than $50 \%$ of missing data were removed and for the rest of the metabolites, any missing data was imputed with one-half of the minimum positive value in the original data assuming their level was below the instrument detection limit. MVA and visualization was performed with SIMCA-P+ 12.0 software (Umetrics AB, Umeå, Sweden) and MetaboAnalyst (Xia \& Wishart 2011) using log-transformed and autoscaled data and validated by sevenfold Cross-Validation and permutation with 500 random. To address the problem of multiple comparisons the False Discovery Rate (FDR) test was adopted. (Storey 2002).

\section{Data analysis}

Protein, oil, and elemental data were analyzed using R and the packages dplyr, ggplot2, grid, reshape2, qtlcharts and gplots. All data and analysis scripts used in the analysis are included as a supplemental file and are available on www.ionomicshub.org.

\section{Results}




\section{Canopy position affects soybean seed protein, oil and mineral concentrations}

212 We investigated positional effects with a core group of ten soybean lines (Supplemental Table

213 1) grown in Urbana, IL, over a 3-year period. Main stems were harvested at maturity and divided

214 into four canopy position quadrants (Fig. 1) and the seeds collected from each quadrant were

215 analyzed separately for major storage products (protein and oil) and various minerals.

216 Representative results obtained for one cultivar ('Chamberlain') are presented in Fig. 2A with

217 full plots provides as Supplemental File 1. As shown, protein concentration increased with

218 node position at which seeds developed going from bottom to top of the mainstem while oil and

219 iron $(\mathrm{Fe})$ concentration decreased. For both protein and oil, which are the major seed

220 constituents, there was variation in the absolute concentrations among the 3 years of study, but

221 general trends were similar. Differences in absolute concentrations among years were most

222 apparent for protein concentration with highest levels obtained in 2010 and lowest in 2011,

223 presumably reflecting the impact of weather on seed development and composition. Another

224 confounding source of variation for canopy position analysis is genotype, and Fig. 2B highlights

225 the substantial variation in absolute concentrations of seed constituents due to both genotype and

226 year. As expected, absolute concentrations of Mg, S, K, P and Ca were highest (> 1000 ppm);

$227 \mathrm{Mn}, \mathrm{Fe}, \mathrm{Rb}$, and $\mathrm{Zn}$ were intermediate (10 to $100 \mathrm{ppm}$ ), and $\mathrm{Na}, \mathrm{Co}, \mathrm{Ni}, \mathrm{Cu}, \mathrm{Sr}, \mathrm{Mo}$, and $\mathrm{Cd}$

228 were present at trace levels $(<10 \mathrm{ppm})$.

229 In order to compare positional effects for various parameters across genotypes and years

230 without the confounding effects of differences in absolute values, we normalized each canopy

231 gradient to a mean value of one and the values for each quadrant were then expressed relative to

232 the normalized mean. However, because the weather in each year of the study differed

233 (Suppleemntal Table 2), the normalized results for each parameter are presented separately for

234 each year. Across the 10 soybean lines, oil concentration decreased progressively from bottom

235 to top of the canopy and was associated with a reciprocal increase in protein concentration (Fig.

236 3A). Protein and oil concentrations in soybean seeds are usually inversely related (Wilcox 1998)

237 and this was apparent with variation within the canopy as well. Single seed weight (designated as

238 sample weight in Fig. 3A) varied with canopy position with seed produced in the middle portion

239 tending to be slightly heavier than seeds produced at either the bottom or top of the canopy;

240 however, the storage product gradients were independent of seed weight variation. Storage

241 product gradients did not vary significantly across the three years of the study; however, absolute 
242 protein and oil concentrations varied among the three years of the study (Figure S1), This is

243 perhaps a result of weather that differed substantially in terms of temperature and precipitation 244 among the three growing seasons (Supplemental Table 2).

245 We also found that canopy position significantly affected the seed ionome, which comprises

246 all of the minerals and trace elements found in mature seeds (Fig. 3B and Supplemental File 2).

247 While there have been several studies of the soybean seed ionome (McGrath \& Lobell 2013;

248 Myers et al. 2014; Sha et al. 2012; Ziegler et al. 2013), to our knowledge this is the first report

249 demonstrating variation with canopy position. Figure 3B shows normalized canopy gradient

250 plots for elements where there was a statistically significant $(\mathrm{p}<0.01)$ variation in concentration

251 with position. Several groups of minerals exhibited common responses with canopy position.

252 The elements $\mathrm{Mg}, \mathrm{Fe}, \mathrm{Cu}$, and $\mathrm{Cd}$ were present at highest concentrations in seeds from the

253 bottom of the canopy and decreased progressively to the top of the canopy. Within this group,

254 the profiles for $\mathrm{Mg}$ and Fe were similar to one another in that variation was relatively low and

255 the gradients were almost identical across the three years; however, the relative changes in $\mathrm{Fe}$

256 concentration were much greater in magnitude compared to changes in $\mathrm{Mg}$ concentration. $\mathrm{Cu}$,

$257 \mathrm{Zn}$ and $\mathrm{Cd}$ showed similar patterns, but were more variable among years. The second group that

258 was apparent included $\mathrm{Ca}$ and $\mathrm{Sr}$, where seeds from the middle of the canopy exhibited the

259 lowest concentrations except in 2010, when concentrations of both $\mathrm{Ca}$ and $\mathrm{Sr}$ tended to increase

260 going up the canopy. Finally, Mn was alone in the third category that increased in concentration

261 towards the top of the canopy in all 3 years. $\mathrm{Ca}$ and $\mathrm{Sr}$, and $\mathrm{Cd}$ and $\mathrm{Zn}$, are chemically similar

262 which may explain their parallel profiles. It is interesting to note that while $\mathrm{Rb}$ is a chemical

263 analog of K and the two are often closely correlated (Baxter 2009), that was not the case for

264 soybean seeds where significant position effects on Rb were observed (Fig. 3B) but not for K

265 (see Supplemental file 2) It is also noteworthy that 2010 was the one year where mineral

266 profiles were often distinct from those in 2011 and 2012. All three years were above normal in

267 terms of temperature, but 2010 was the only year with above normal precipitation. Thus, water

268 availability may be a major environmental factor impacting positional effects on the seed

269 ionome, and interestingly some minerals were affected (Ca, $\mathrm{Mn}, \mathrm{Cu}, \mathrm{Zn}, \mathrm{Sr})$ while others $(\mathrm{Mg}$,

$270 \mathrm{Fe}, \mathrm{Co}, \mathrm{Rb}, \mathrm{Cd})$ were not. We also measured other minerals (B, Na, Al, P, S, K, Ni, As, Se and

271 Mo) that did not show statistically significant variation with nodal position and are presented in

272 Supplemental File 2. 
273

274

275

276

277

278

279

280

281

282

283

284

285

286

287

288

289

290

291

292

293

294

295

296

297

298

299

300

301

302

303

Another way to compare canopy profiles for the minerals measured is to do an overall correlation matrix of quadrant variation normalized to plot averages. In this way, one can look across the entire data set for parameters that are correlated based on variation with nodal position. A strong positive correlation would indicate that both components changed not only in the same direction but also to the same relative extent. As shown in Fig. $\mathbf{4 A}$, only a few strong correlations were apparent among the measured parameters. Variation in seed size (sample weight in Fig. 4A) did not significantly correlate with positional variation of any of the measured elements or storage products. Protein and oil concentrations were strongly negatively correlated, as expected. In terms of minerals and storage products, the quadrant variation in protein concentration correlated negatively with $\mathrm{Fe}$ and $\mathrm{Cu}$, and positively with $\mathrm{Mn}$, and the reciprocal pattern was apparent with oil concentration. Among the minerals, highly correlated element pairs included Fe-Cu, Ca-Sr, Ca-Mn, and $\mathrm{Zn}-\mathrm{Cu}$, and between $\mathrm{P}$ and $\mathrm{S}, \mathrm{Zn}$, and $\mathrm{Co}$. As noted earlier, $\mathrm{Ca}$ and $\mathrm{Sr}$ are chemical analogs and frequently correlated (Baxter 2009), but surprisingly, other chemical analog pairs such as $\mathrm{K}-\mathrm{Rb}$ were not observed. Fe and $\mathrm{Cu}$ were positively paired and have been reported to be positively correlated in soybean seeds (Vasconcelos et al. 2014) but the basis for the pairing is unknown. Correlations between $\mathrm{P}$ and minerals are often considered to reflect association of the mineral with seed phytate, the principal form of $\mathrm{P}$ in seeds (Vreugdenhil et al. 2004).

In addition to comparing parameters based on quadrant variation, it is also worthwhile to compare plot averages, which will reflect genetic and environmental effects on absolute values of the parameters. Figure 4B shows a matrix plot of correlations between plot means. Compared to the corresponding plot that focused on quadrant variation (Fig. 4A), many more strong correlations were apparent when comparing plot means. For example, protein concentration was positively correlated with $\mathrm{S}$ and $\mathrm{Zn}$ (and more weakly with Fe). The correlation with $\mathrm{S}$ is expected as the total seed $\mathrm{S}$ has been shown to track closely with high cysteine- and methioninecontaining proteins in the soybean seed (Krishnan et al. 2012). The correlations between protein content, $\mathrm{Zn}$ and Fe could be due to their primary role as cofactors of metalloproteins or to variations senescence in leaves leading to nutrient remobilization (Uauy et al. 2006).

Accordingly, there was a significant negative correlation of $\mathrm{Fe}, \mathrm{S}$, and $\mathrm{Zn}$ with oil concentration. Interestingly, there was also a strongly significant negative correlation of $\mathrm{P}$ with oil, whereas the positive correlation of $\mathrm{P}$ with protein concentration was relatively weak. The majority of mineral 
304 correlations were positive in nature, with a maxi-cluster of $\mathrm{Rb}, \mathrm{Mn}, \mathrm{Sr}, \mathrm{Mg}, \mathrm{Ni}$, and $\mathrm{Na}$ and a

305 mini-cluster of $\mathrm{Fe}, \mathrm{Cu}$ and $\mathrm{Zn}$. The mini-cluster pairs of $\mathrm{Fe}-\mathrm{Cu}$ and $\mathrm{Cu}-\mathrm{Zn}$ were noted in the plot

306 of Fig. 4A, but several members of the maxi-cluster correlation were not reported in the plot

307 normalized correlation matrix. For example, $\mathrm{Mn}$ and $\mathrm{Mg}$ concentrations did not relate to each

308 other in terms of quadrant variation but were strongly positively correlated based on plot means,

309 indicating that mineral uptake may be similar but allocation among seeds in different quadrants

310 is controlled separately. Finally, P concentration exhibited a positive correlation with $\mathrm{Mn}, \mathrm{Fe}$,

$311 \mathrm{Cu}, \mathrm{Zn}, \mathrm{S}$ and $\mathrm{Co}$. The link among $\mathrm{P}$ and $\mathrm{Zn}, \mathrm{S}$ and $\mathrm{Co}$ concentrations with quadrant variation

312 was observed (Fig. 4A), but when analyzed in terms of plot means in Fig. 4B the association of

$313 \mathrm{P}$ with $\mathrm{Mn}, \mathrm{Fe}$, and $\mathrm{Cu}$ became apparent as well. It is worth noting that in terms of plot means,

314 there was no association between $\mathrm{Ca}$ and $\mathrm{Sr}$ suggesting that these chemical analogs do not

315 always behave similarly. There was one also a strong negative correlation between Mo and $\mathrm{Sr}$,

316 and Mo and S, perhaps suggesting a common component(s) of the uptake system. Readers can

317 explore all of the correlations and the underlying data in using Supplemental Files 3,4 and 5.

318

319

320

321

322

323

324

325

326

327

328

329

330

331

332

333

334

\section{Canopy microenvironment impacts seed composition}

Our understanding of the environmental factors responsible for the positional effects on seed composition is limited; however, many microclimatic factors vary from the top to the bottom of the closed soybean canopy (Baldocchi et al. 1983). Environment is well known to impact soybean seed protein and oil composition (Rotundo \& Westgate 2009). Therefore, we conducted experiments to broadly evaluate microclimatic differences within the canopy by thinning plants at flowering to remove the influence of neighboring plants. Removal of neighboring plants increased protein concentration at the expense of oil in seeds throughout the canopy of the spaced plants but the changes were greatest in pods lower on the main stem. As a result, the thinning treatment reduced the positional effect on protein and oil by $50-60 \%$ (Fig. 5A).

Increased light energy to drive photosynthesis at most leaf positions and increased temperature at lower positions could both favor increased protein accumulation at lower nodes thereby reducing the difference between top and bottom seeds. However, while thinning significantly altered the main stem gradients in major storage products there was relatively little effect on minerals. As shown in Fig. 5B, the canopy positional effect on $\mathrm{Mg}, \mathrm{Fe}$ and $\mathrm{Cu}$ was unaltered by the thinning treatment whereas $\mathrm{Ca}$ and $\mathrm{Sr}$ were similar to one another and showed a significant effect of thinning but only in one of the two test years (2010). The general conclusion is that thinning 
335

336

337

338

339

340

341

342

343

344

345

346

347

348

349

350

351

352

353

354

355

356

357

358

359

360

361

362

363

364

365

affects the canopy positional effect on some but not all minerals. This suggests that at least for $\mathrm{Mg}, \mathrm{Fe}$ and $\mathrm{Cu}$, the transport and homeostasis mechanisms are generally independent of instantaneous environmental factors and the transport of sucrose and amino acids into the developing seeds is not the sole factor driving their movement into seeds.

\section{Seed fill period and seed composition}

Another factor that could contribute to canopy position effects on seed composition is the duration of the seed-fill period (SFP), which is affected by genetic and environmental factors and is one of the major determinants of yield potential in soybean (Evans et al. 1995). Soybeans flower in response to photoperiod and the first flowers form lower in the canopy followed by flowering at upper nodes. Pods then form in the same order and when fully elongated the process of seed development is considered to begin when seeds are approximately 0.34 centimeter long (by visual inspection). In general, seeds lower in the canopy fill over a longer period but at a lower rate compared to seeds at the top of the canopy (Raboy \& Dickinson 1987) so that at maturity, final seed size tends to be rather constant through the canopy rather than increasing progressively from bottom to top of the canopy. We measured the SFPs with our core group of ten lines and found substantial differences in SFPs at the bottom and top of the canopy (Supplemental Table 3). Top SFP was generally correlated with bottom SFP, as would be expected, but the difference in SPF (bottom - top position) was not correlated with the canopy gradients of protein, oil, or Fe (Fig. 6). Therefore, factors other than the duration of the SFP are responsible for the documented variation in composition with nodal position.

\section{Iron concentrations of soybean seed products}

Our results raise the question of whether soy food products made from seed from different portions of the canopy would vary in terms of their mineral concentrations. Three of the most common and simplest products to make from soybean seeds are flour, milk and okara (the particulate material remaining after preparation of milk). Because Fe is one of the most critical minerals to human health and anemia is a global epidemic, we focused our initial analysis on the Fe content of these soy food products. We prepared flour from seven lines, and milk and okara from four lines and Fig. 7 summarizes the results (All elements displayed in Supplemental file 6). With all three products, the concentration of Fe was highest in products made from seeds 
366 produced at the bottom of the canopy and decreased progressively with canopy position of the

367 seeds used. Thus, as would be expected the concentration of seed Fe affects the concentration of

$368 \mathrm{Fe}$ in the flour, milk or okara produced from those seeds. Although many questions remain, the

369 public health implications of our findings are apparent. Given that mineral content of seeds,

370 especially Fe, is important our results uncover another source of variation that can be directly

371 exploited.

372

373 The vegetative soybean ionome

374 The canopy effect on seed mineral concentration prompted us to look at the distribution of

375 minerals in the shoots of vegetative plants. Minerals deposited in seeds are derived from

376 continued uptake from the soil or remobilization of previously accumulated minerals (Hocking \&

377 Pate 1977; Waters \& Grusak 2008), and therefore the leaf ionome of the vegetative plant is

378 relevant to studies of the mature seed ionome. Consequently, we examined the leaf ionome from

379 four genotypes as a function of canopy position. As shown in Fig. 8, the concentrations of $\mathrm{Mg}$,

$380 \mathrm{Al}, \mathrm{Ca}, \mathrm{Mn}, \mathrm{Fe}, \mathrm{Co}, \mathrm{As}$, and $\mathrm{Sr}$ were highest in leaves at the bottom of the canopy and decreased

381 progressively to the top of the canopy. Concentrations of $\mathrm{P}, \mathrm{S}, \mathrm{K}, \mathrm{Cu}, \mathrm{Zn}, \mathrm{Rb}$, and Mo increased

382 from bottom to top leaves. $\mathrm{Na}$ and $\mathrm{Ni}$ were present at low absolute concentrations and fluctuated

383 but not in a progressive pattern as for the other minerals. Although leaves at different positions

384 are often analyzed together (or as part of the 'shoot'), two previous studies with soybean also

385 reported differences in mineral concentrations of lower, middle and upper leaves (Drossopoulos

386 et al. 1994) or young and old leaves (corresponding to different node positions) (Duke et al.

387 2012) that are generally consistent with our results. The basis for differential accumulation of

388 foliar minerals at different positions within the canopy is not clear and will be important to

389 address in future studies. One possible explanation is that the greater phloem mobility of $\mathrm{P}$ and $\mathrm{K}$

390 facilitates their enhanced remobilization to upper nodes whereas other less mobile elements (e.g.

$391 \mathrm{Fe}, \mathrm{Ca}$, and $\mathrm{Mg}$ ) tend to remain at their point of initial deposition. This would not readily

392 explain the observed profiles for $\mathrm{Cu}, \mathrm{Zn}$ and Mo, however, highlighting the complexities

393 involved in metal homeostasis and the significant variation with canopy position. Another

394 working hypothesis could be that $\mathrm{K}, \mathrm{P}, \mathrm{Cu}, \mathrm{Zn}$ and Mo are mineral markers of metabolic activity

395 and accumulate in leaves at the top of the canopy that have highest rates of photosynthesis.

396 Because minerals can be remobilized from leaves to developing seeds (Drossopoulos et al. 1994; 
397 Jiménez et al. 1996; Sankaran \& Grusak 2014), it is tempting to speculate that canopy seed

398 gradient in Fe and $\mathrm{Mg}$ may be related to greater stores of both metals in leaves lower in the 399 canopy. Opposite patterns were observed for other minerals ( $\mathrm{Ca}, \mathrm{Mn}$, and $\mathrm{Cu}$ ) suggesting that

400 remobilization is either mineral specific or not quantitatively important in delivery of minerals to 401 developing seeds.

402 A final point to note is that the potential exists for some soil particles to adhere to vegetative 403 plant parts, especially lower in the canopy, while seeds are protected from soil contamination by 404 the pods. Since some minerals exhibited opposite patterns, it seems that soil adhesion could not 405 be completely responsible for the patterns observed.

406

\section{Node position and the developing seed metabolome}

408

409

410

411

412

413

414

415

416

417

418

419

420

421

422

423

424

425

426

427

Developing seeds were analyzed to determine whether canopy position affected seed metabolism sufficiently to explain the observed differences in protein and oil concentrations at maturity. To do this, we collected developing seeds (cultivar 'Williams 82') from the top and bottom of the canopy at several time points over a $24-\mathrm{h}$ period as illustrated in Figure S2. Because seeds at the top and bottom of the canopy differed in size on the day of the experiment, seeds from the top of the canopy were also collected 6 days later when they had reached the same size (fresh weight seed $^{-1}$ ) as the bottom seeds on the first collection date. All seeds were at the stage of development where cell expansion and accumulation of storage compounds (protein and oil) were the dominant metabolic processes (Collakova et al. 2013). Untargeted metabolite profiling was conducted for analysis of polar compounds, free amino acids, free fatty acids, and total fatty acids (Supplemental File 7).

In general, most metabolites did not show diurnal changes in concentration, but there were differences in concentrations as a function of seed size and node position. The metabolite plots in Fig. 9 illustrate some of the different patterns observed. The concentration of sucrose (Fig. 9A) in developing seeds did not vary diurnally and remained relatively constant but the concentration was slightly higher in the smallest seeds (day 1, top seed) compared to the larger seeds sampled at the bottom position on day 1 or top position on day 7. The decrease in sucrose concentration comparing top seed on day 1 and day 7 likely reflects in part the dilution effect caused by storage product accumulation as the seeds increased in size by roughly 2-fold. In contrast, the concentration of citrate in developing seeds was roughly equal among the three samples (Fig. 
428 9B). These results suggest that seeds actually accumulate sucrose and to a larger extent citrate as 429 they increase in dry matter during seed fill (thereby negating the dilution effect caused by seed

430

431

432

433

434

435

436

437

438

439

440

441

442

443

444

445

446

447

448

449

450

451

452

453

454

455

456

457

growth). This also indicates that developing seeds have ample sugars and organic acids

irrespective of size and node position and time of day. In marked contrast to sucrose and citrate were the dramatic differences observed in free asparagine (Asn) concentration (Fig. 9C), which was highest in top seed sampled on day 1 (Aug 20), and lowest in bottom seed sampled on the same day; the difference was roughly 8-fold. Sampling top seed on day 7 (Aug 26), when seed size was equivalent to that of bottom seed on day 1 , still resulted in a $\sim 4$-fold elevation of free Asn concentration. The roughly 2-fold decrease in Asn concentration in seeds at the top of the canopy from day 1 to day 7 likely reflects the dilution effect of growth. The pattern for Asn concentration is potentially of interest because free Asn concentration during seed development correlates with protein concentration at maturity (Herman 2014b; Hernandez-Sebastia et al. 2005; Miller et al. 2008; Pandurangan et al. 2012). The results obtained in the present study suggest that greater supply of Asn to developing seeds at the top of the canopy may contribute to the observed greater accumulation of storage protein.

Importantly, Asn was also one of the important metabolites that distinguished the three sets of seeds collected based on a global metabolite analysis (Supplemental File 8). Mean values for Asn, and other protein amino acids are shown in Fig. 10. The concentrations of the free amino acids was highest in the small seed (top seed, day 1). Concentrations of Ala, Asn, Gly, and Thr were substantially higher in top seed at day 7 relative to bottom seed at day 1 (when seed sizes were similar). Of those amino acids, Asn was present at the highest absolute concentrations and may contribute to the storage protein biosynthesis either by acting as a signal metabolite or providing substrate for protein biosynthesis.

\section{Discussion}

The present study yields two major conclusions. First, the position along the main stem at which soybean seeds develop has a profound impact on seed composition, affecting the concentrations of protein, oil and certain minerals at maturity. Second, the canopy position effects on seed mineral concentrations (in particular Fe) are sufficiently large that there may be direct 
458 implications for human nutrition in countries where plants are the main source of protein and

459 soybeans are used for human food. These conclusions are discussed in more detail below.

460

461

Positional effects on seed protein and oil concentration are broadly observed

462 Results of the present study demonstrate that for 10 lines grown over a period of 3 years there

463 were remarkably consistent gradients in protein and oil concentrations in mature seeds as a

464 function of nodal position (Figs. 2A and 3). Increased concentration of oil in seeds from lower

465 nodes could result from the increased duration of the SFP documented for lower pods

466 (Supplemental Table 3) because the accumulation of oil in seeds often starts earlier than protein

467 (Rotundo \& Westgate 2009; Saldivar et al. 2011). However, oil accumulation tends to plateau

468 before protein accumulation and therefore, percent oil will often decrease with increasing

469 duration of the SFP rather than increase. In the present study, the protein and oil concentration

470 gradients from bottom to top of the canopy were not correlated with the difference in SFP

471 between the two positions (Fig. 6) and thus it appears that SFP does not determine the observed

472 gradients in protein and oil concentration. Micro-environment appears to be one factor

473 controlling protein and oil concentration gradients in the canopy because removal of neighboring

474 plants at flowering increased protein concentration at all positions and decreased the difference

475 between top and bottom nodes (Fig. 5). While it is not clear which micro-environmental

476 factor(s) might actually be involved, we suggest that increased light energy reaching lower

477 leaves may be a contributing factor. Metabolomic analysis of developing seeds that identified

478 free Asn as one of the primary metabolites distinguishing seeds at the bottom and top of the

479 canopy supports this conclusion. Asparagine is the major free amino acid in developing soybean

480 seeds and differences in Asn concentration during development are positively correlated with

481 protein concentration at seed maturity (Hernandez-Sebastia et al. 2005; Pandurangan et al. 2012).

482 Furthermore, over-expression of asparaginase in soybean, driven by an embryo-specific

483 promoter, resulted in a reduction in free Asn concentration during development and reduced

484 protein concentration in mature seed, measured by nitrogen analysis (Pandurangan et al. 2015).

485 Collectively, these results suggest that free Asn is a sensor or regulator of processes that

486 determine protein accumulation in soybean seeds (Herman 2014a). Our results are consistent

487 with this hypothesis and suggest that differences in free Asn concentration may explain the

488 position effects on seed protein (and oil) concentration. Nitrogen and carbon flux into pods is 
489 largely provided by nearest sources (Seddigh \& Jolliff 1986; Streeter \& Jeffers 1979) including 490 the nearest trifoliolate leaves. We speculate that decreased light at lower positions in the closed 491 canopy (i.e., with neighboring plants) would reduce leaf metabolism as well as the xylem flux of 492 ureides and/or nitrate from roots to the lower leaves, thereby restricting the ability of those leaves 493 to provide Asn (and Gln) to developing seeds. In contrast, removal of neighboring plants (in the 494 'thinned' plant treatment) would increase light at lower nodes thereby enhancing overall leaf 495 metabolism and the flux of reduced nitrogen to subtending pods resulting in increased protein 496 (and reduced oil) accumulation.

497

\section{Positional effects on seed mineral concentration are documented}

The concentration of minerals in seeds reflects the combined action of transport processes and regulation at multiple steps starting with mobilization from the soil, uptake into the root, and transport to the shoot for distribution among organs (Grusak et al. 1999; Waters \& Grusak 2008). Deposition of some minerals in seeds can also involve remobilization from leaves during seed filling (Grusak et al. 1999; Hocking \& Pate 1977), and it is interesting that different minerals show fundamentally different profiles of accumulation in seeds as a function of canopy position (Fig. 3). These differences could reflect alternate routes from the apoplast to the symplast or differences in mobility in the phloem (White 2012). Interestingly, minerals that tended to have highest concentrations in seeds at the bottom of the canopy (e.g., $\mathrm{Mg}, \mathrm{Fe}$, and $\mathrm{Cu}$ ) are considered to have moderate to good phloem mobility compared to the minerals that tended to concentrate in the top of the canopy such as $\mathrm{Mn}$ (and in some cases $\mathrm{Ca}$ ) that are considered to have poor phloem mobility. These results suggest that remobilization from leaves may be playing some role at least in the positional effects on the mature seed ionome. Another factor that may impact the

512 distribution of minerals in seeds along the mainstem is precipitation. This speculation is based on 513 the increased concentrations of $\mathrm{Ca}, \mathrm{Mn}$, and $\mathrm{Sr}$ found in seeds at the top of the canopy in 2010, 514 which had above normal precipitation. It is possible that increased precipitation resulted in 515 greater xylem transport of certain minerals (including $\mathrm{Ca}, \mathrm{Mn}$, and $\mathrm{Sr}$ ) to developing seeds at the 516 top of the canopy, or alternatively, that weather conditions in 2010 allowed greater

517 remobilization of selected minerals from leaves via the xylem. It is recognized that while Ca and 518 Mn are generally considered to have very low phloem mobility and are therefore not remobilized 519 from senescing leaves, there is variation among species in the extent of remobilization (Maillard 
520 et al. 2015). Conceivably, remobilization may also be triggered from leaves of all species under

521 certain conditions.

522 While multiple seed constituents exhibited canopy concentration gradients, it seems

523 unlikely that they are all caused by the same factors. Changing the microenvironment by

524 thinning plants to allow increased light penetration into the canopy altered the protein and oil

525 gradients but did not affect observed gradients for most of the minerals (Fig. 5). Furthermore,

526 while the slope of many gradients changes across lines, treatment and year, the way that they

527 change is not well correlated between the different constituents, as illustrated in the plot

528 normalized correlation matrix (Fig. 4A), where relatively few strong correlations among the

529 various parameters were apparent. However, numerous correlations were apparent when mean

530 plot values were compared (Fig. 4B). Several minerals (e.g., P, Mn, Fe, Zn, S, and Co) had a

531 negative relationship with oil concentration and increased with protein concentration. Thus,

532 some coordination between seed storage product accumulation and mineral uptake into seeds is

533 evident. However, the results suggest that total uptake of a mineral and the allocation among

534 nodal positions are controlled by different mechanisms, and in general, canopy positional effects

535 on minerals and protein/oil appear to be controlled by distinct mechanisms. It should be noted

536 that altering the microenvironment by thinning plants did affect the observed gradients in seed

537 concentrations of $\mathrm{Ca}, \mathrm{Mn}$, and $\mathrm{Sr}$, which were also the minerals altered in distribution in 2010

538 (the year of this study with above normal precipitation). These results highlight the differences

539 among minerals in terms of factors controlling their distribution among seed produced at

540 different node positions. Clear, continued studies in the future will be required to sort out the

541 different mechanisms involved.

542

543 Human nutrition implications for variation in seed composition

544 Soybeans are valued for their protein and oil content, but when used for human nutrition the

545 content of minerals such as iron and zinc is also critically important. On a global scale, human

546 iron deficiency is one of the most prevalent nutritional disorders (McLean et al. 2009) especially

547 in countries where plant-based diets are prominent. As discussed above, nodal position affected

548 the concentration of several minerals such as $\mathrm{Mg}, \mathrm{Fe}$, and $\mathrm{Cu}$ that were present at higher

549 concentrations in seeds produced at the bottom of the canopy. Iron is of particular interest and

550 was generally $20 \%$ higher in seeds produced lower in the canopy relative to the top and as 
551 expected, differences in seed iron concentrations affected the concentration of iron in soy food

552 products made from those seeds (Fig. 7). Soy flour preserved more Fe than did milk; perhaps

553 mineral retention improvement through product preparation is possible. An immediate

554 application of our results with respect to human nutrition would be to use seeds from the top and

555 bottom halves of the canopy for different purposes, with seeds produced in the lower half

556 reserved for production of iron-rich soy foods for human consumption. Thus, knowledge of

557 these canopy position effects provides an unexpected approach to link agronomic practices to

558 improve human nutrition and health.

559

560

New type of seed heteromorphism and implications for climate change impacts

561

Seed heteromorphism is well established (Matilla et al. 2005) but the seed heterogeneity

562 documented here establishes a new category where an individual plant produces a continuum of

563 seeds that differ in major aspects of their composition (protein, oil, and minerals) but are morphologically very similar. Overall, our results raise a number of questions and directions for future research. For example, it would be interesting to explore whether there are positional effects on soybean seed functional traits such as seed vigor or seedling stress tolerance. Because environment during reproductive development of plants is now recognized to broadly impact seed properties, such as growth performance and stress tolerance of the progeny (Biodner et al. 2007; Tricker et al. 2013), it will be interesting to further explore similar properties of soybean seed produced at the different parts of the canopy. Our results also raise the question of whether similar effects occur in other species including non-domesticated plants where there might be some ecological significance.

Another area that will be interesting to explore is the impact of elevated $\mathrm{CO}_{2}$ on the canopy positional effects described in the present study. It was recently reported (Loladze 2014; Myers et al. 2014) that grain from many species, including soybean, have lower concentrations of $\mathrm{Zn}$ and $\mathrm{Fe}$ when plants are grown at elevated $\mathrm{CO}_{2}$ thereby uncovering a new climate change challenge to global health. The meta-analysis established a $\sim 5 \%$ reduction in soybean seed $\mathrm{Fe}$ and $\mathrm{Zn}$ concentrations at high $\mathrm{CO}_{2}$. It is relevant to note that variation in seed Fe concentration with node position established in the present study is substantially larger (4-fold greater) compared to the impact of climate change on mean seed Fe concentration. Therefore, our results are likely to be meaningful from a quantitative standpoint and have important implications for 
582 examining the impact of climate change on the seed ionome. For example, it will be interesting 583 to determine how this overall reduction in mean seed Fe concentration at elevated $\mathrm{CO}_{2}$ is related 584 (if at all) to canopy position effects; is Fe reduced 5\% in seeds at nodes throughout the canopy 585 or are certain positions affected to a greater degree than others? Identifying the molecular 586 mechanisms underlying canopy gradients in composition may provide new approaches to 587 controlling soybean seed quality for various uses, including food for human consumption under 588 conditions of global climate change.

589

590

591 


\section{Acknowledgements}

594 The authors thank Kunming University of Science and Technology (KUST), Kunming City, P.R.

595

596

597

598

599

600

601

602

603

604

605

606

607

608

609

610

611

612

613

614

615

616

617

618

619

620

621

622

623

624

625

626

627

628

629

630

631

632

China for supporting the visit of Prof. Kunzhi Li to UIUC; Karl E. Weingarter and Marilyn L.

Nash for advice on soy food preparation and providing access to the Test Kitchen facility of the

National Soybean Research Laboratory at the University of Illinois; Greg Ziegler for expert

technical assistance with ionomic analysis and Sarah Schultz for help with field sampling.

Support for this work was provided by the United Soybean Board and the USDA-ARS.

\section{REFERENCES}

Baldocchi DD, Verma SB, and Rosenberg NJ. 1983. Microclimate in the soybean canopy. Agricultural Meteorology 28:321-337. http://dx.doi.org/10.1016/0002-1571(83)90009-2

Baxter I. 2009. Ionomics: studying the social network of mineral nutrients. Current Opinion in Plant Biology 12:381-386. http://dx.doi.org/10.1016/i.pbi.2009.05.002

Biodner C, Goebel C, Feussner I, Gatz C, and Polle A. 2007. Warm and cold parental reproductive environments affect seed properties, fitness, and cold responsiveness in Arabidopsis thaliana progenies. Plant, Cell \& Environment 30:165-175. 10.1111/j.1365-3040.2006.01615.x

Carrera C, Martínez MJ, Dardanelli J, and Balzarini M. 2009. Water Deficit Effect on the Relationship between Temperature during the Seed Fill Period and Soybean Seed Oil and Protein Concentrations. Crop Science 49:990-998. 10.2135/cropsci2008.06.0361

Carrera C, Martínez MJ, Dardanelli J, and Balzarini M. 2011. Environmental Variation and Correlation of Seed Components in Nontransgenic Soybeans: Protein, Oil, Unsaturated Fatty Acids, Tocopherols, and Isoflavones. Crop Science 51:800-809. 10.2135/cropsci2010.06.0314

Collakova E, Aghamirzaie D, Fang Y, Klumas C, Tabataba F, Kakumanu A, Myers E, Heath L, and Grene R. 2013. Metabolic and Transcriptional Reprogramming in Developing Soybean (Glycine max) Embryos. Metabolites 3:347-372.

Collins FI, and Cartter JL. 1956. Variability in Chemical Composition of Seed From Different Portions of the Soybean Plant1. Agron J 48:216-219. 10.2134/agronj1956.00021962004800050006x

Drossopoulos JB, Bouranis DL, and Bairaktari BD. 1994. Patterns of mineral nutrient fluctuations in soybean leaves in relation to their position. Journal of Plant Nutrition 17:1017-1035. 10.1080/01904169409364785

Duke SO, Reddy KN, Bu K, and Cizdziel JV. 2012. Effects of Glyphosate on the Mineral Content of Glyphosate-Resistant Soybeans (Glycine max). Journal of Agricultural and Food Chemistry 60:6764-6771. 10.1021/jf3014603

Escalante EE, and Wilcox JR. 1993a. Variation in Seed Protein among Nodes of Determinate and Indeterminate Soybean near-Isolines. Crop Science 33:1166-1168.

Escalante EE, and Wilcox JR. 1993b. Variation in Seed Protein among Nodes of Normal-Protein and HighProtein Soybean Genotypes. Crop Science 33:1164-1166.

Evans TA, Fuhrmann JJ, Nelson RL, and Vasilas BL. 1995. Relationship of nitrogen utilization patterns with soybean yield and seed-fill period. Crop Science 35:809+. 
633

634

635

636

637

638

639

640

641

642

643

644

645

646

647

648

649

650

651

652

653

654

655

656

657

658

659

660

661

662

663

664

665

666

667

668

669

670

671

672

673

674

675

676

677

678

679

Grusak MA, DellaPenna D, and Welch RM. 1999. Physiologic processes affecting the content and distribution of phytonutrients in plants. Nutrition reviews 57:27-33.

Herman E. 2014a. Soybean Seed Proteome Rebalancing. Frontiers in Plant Science 5. 10.3389/fpls.2014.00437

Herman EM. 2014b. Soybean seed proteome rebalancing. Front Plant Sci 5:437. $10.3389 /$ fpls.2014.00437

Hernandez-Sebastia C, Marsolais F, Saravitz C, Israel D, Dewey RE, and Huber SC. 2005. Free amino acid profiles suggest a possible role for asparagine in the control of storage-product accumulation in developing seeds of low- and high-protein soybean lines. J Exp Bot 56:1951-1963. 10.1093/jxb/eri191

Hocking PJ, and Pate JS. 1977. Mobilization of Minerals to Developing Seeds of Legumes. Annals of Botany 41:1259-1278.

Jiménez MP, Effrón D, de la Horra AM, and Defrieri R. 1996. Foliar potassium, calcium, magnesium, zinc, and manganese content in soybean cultivars at different stages of development. Journal of Plant Nutrition 19:807-816. 10.1080/01904169609365163

Krishnan HB, Jang S, Baxter I, and Wiebold WJ. 2012. Growing location has a pronounced effect on the accumulation of cancer chemopreventive agent Bowman-Birk inhibitor in soybean seeds. Crop Science 52. 10.2135/cropsci2011.11.0593

Loladze I. 2014. Hidden shift of the ionome of plants exposed to elevated CO2 depletes minerals at the base of human nutrition. Elife 3. 10.7554/eLife.02245

Maillard A, Diquélou S, Billard V, Laîné P, Garnica M, Prudent M, Garcia-Mina J-M, Yvin J-C, and Ourry A. 2015. Leaf mineral nutrient remobilization during leaf senescence and modulation by nutrient deficiency. Frontiers in Plant Science 6:317. 10.3389/fpls.2015.00317

Matilla A, Gallardo M, and Puga-Hermida MI. 2005. Structural, physiological and molecular aspects of heterogeneity in seeds: a review. Seed Science Research 15:63-76. doi:10.1079/SSR2005203

McGrath JM, and Lobell DB. 2013. Reduction of transpiration and altered nutrient allocation contribute to nutrient decline of crops grown in elevated $\mathrm{CO}(2)$ concentrations. Plant Cell Environ 36:697705. 10.1111/pce.12007

McLean E, Cogswell M, Egli I, Wojdyla D, and de Benoist B. 2009. Worldwide prevalence of anaemia, WHO Vitamin and Mineral Nutrition Information System, 1993-2005. Public Health Nutr 12:444454. 10.1017/S1368980008002401

Miller AJ, Fan X, Shen Q, and Smith SJ. 2008. Amino acids and nitrate as signals for the regulation of nitrogen acquisition. $J$ Exp Bot 59:111-119. 10.1093/jxb/erm208

Myers SS, Zanobetti A, Kloog I, Huybers P, Leakey AD, Bloom AJ, Carlisle E, Dietterich LH, Fitzgerald G, Hasegawa T, Holbrook NM, Nelson RL, Ottman MJ, Raboy V, Sakai H, Sartor KA, Schwartz J, Seneweera S, Tausz M, and Usui Y. 2014. Increasing CO2 threatens human nutrition. Nature 510:139-142. 10.1038/nature13179

Pandurangan S, Pajak A, Molnar SJ, Cober ER, Dhaubhadel S, Hernandez-Sebastia C, Kaiser WM, Nelson RL, Huber SC, and Marsolais F. 2012. Relationship between asparagine metabolism and protein concentration in soybean seed. J Exp Bot 63:3173-3184. 10.1093/jxb/ers039

Pandurangan S, Pajak A, Rintoul T, Beyaert R, Hernandez-Sebastia C, Brown DC, and Marsolais F. 2015. Soybean seeds overexpressing asparaginase exhibit reduced nitrogen concentration. Physiol Plant. 10.1111/ppl.12341

Raboy V, and Dickinson DB. 1987. The timing and rate of phytic Acid accumulation in developing soybean seeds. Plant Physiol 85:841-844.

Rotundo JL, and Westgate ME. 2009. Meta-analysis of environmental effects on soybean seed composition. Field Crops Research 110:147-156. http://dx.doi.org/10.1016/i.fcr.2008.07.012 
680

681

682

683

684

685

686

687

688

689

690

691

692

693

694

695

696

697

698

699

700

701

702

703

704

705

706

707

708

709

710

711

712

713

714

715

716

717

718

719

720

721

722

723

724
Saldivar X, Wang Y-J, Chen P, and Hou A. 2011. Changes in chemical composition during soybean seed development. Food Chemistry 124:1369-1375. http://dx.doi.org/10.1016/j.foodchem.2010.07.091

Sankaran RP, and Grusak MA. 2014. Whole shoot mineral partitioning and accumulation in pea (Pisum sativum). Front Plant Sci 5:149. 10.3389/fpls.2014.00149

Seddigh M, and Jolliff GD. 1986. Remobilization Patterns of C and N in Soybeans with Different SinkSource Ratios Induced by Various Night Temperatures. Plant Physiology 81:136-141.

Sha Z, Oka N, Watanabe T, Tampubolon BD, Okazaki K, Osaki M, and Shinano T. 2012. Ionome of soybean seed affected by previous cropping with mycorrhizal plant and manure application. $J$ Agric Food Chem 60:9543-9552. 10.1021/jf3024744

Storey JD. 2002. A direct approach to false discovery rates. Journal of the Royal Statistical Society: Series B (Statistical Methodology) 64:479-498. 10.1111/1467-9868.00346

Streeter JG, and Jeffers DL. 1979. Distribution of Total Non-Structural Carbohydrates in Soybean Plants Having Increased Reproductive Load. Crop Science 19:729-734. 10.2135/cropsci1979.0011183X001900050046x

Tricker P, López C, Gibbings G, Hadley P, and Wilkinson M. 2013. Transgenerational, Dynamic Methylation of Stomata Genes in Response to Low Relative Humidity. International Journal of Molecular Sciences 14:6674-6689.

Uauy C, Distelfeld A, Fahima T, Blechl A, and Dubcovsky J. 2006. A NAC Gene Regulating Senescence Improves Grain Protein, Zinc, and Iron Content in Wheat. Science 314:1298-1301. 10.1126/science.1133649

Vasconcelos MW, Clemente T, and Grusak MA. 2014. Evaluation of constitutive iron reductase (AtFRO2) expression on mineral accumulation and distribution in soybean (Glycine max. L). Frontiers in Plant Science 5. 10.3389/fpls.2014.00112

Vreugdenhil D, Aarts MGM, Koornneef M, Nelissen H, and Ernst WHO. 2004. Natural variation and QTL analysis for cationic mineral content in seeds of Arabidopsis thaliana. Plant, Cell \& Environment 27:828-839. 10.1111/j.1365-3040.2004.01189.x

Waters BM, and Grusak MA. 2008. Whole-plant mineral partitioning throughout the life cycle in Arabidopsis thaliana ecotypes Columbia, Landsberg erecta, Cape Verde Islands, and the mutant line ysl1ys|3. New Phytol 177:389-405. 10.1111/j.1469-8137.2007.02288.x

White PJ. 2012. Chapter 3 - Long-distance Transport in the Xylem and Phloem A2 - Marschner, Petra. Marschner's Mineral Nutrition of Higher Plants (Third Edition). San Diego: Academic Press, 4970.

Wilcox JR. 1998. Increasing Seed Protein in Soybean with Eight Cycles of Recurrent Selection. Crop Sci 38:1536-1540. 10.2135/cropsci1998.0011183X003800060021x

Wolf RB, Cavins JF, Kleiman R, and Black LT. 1982. Effect of temperature on soybean seed constituents: Oil, protein, moisture, fatty acids, amino acids and sugars. Journal of the American Oil Chemists' Society 59:230-232. 10.1007/BF02582182

Xia J, and Wishart DS. 2011. Web-based inference of biological patterns, functions and pathways from metabolomic data using MetaboAnalyst. Nat Protocols 6:743-760.

Ziegler G, Terauchi A, Becker A, Armstrong P, Hudson K, and Baxter I. 2013. Ionomic Screening of FieldGrown Soybean Identifies Mutants with Altered Seed Elemental Composition. The Plant Genome 6. 10.3835/plantgenome2012.07.0012 
725

726

727

728

729

730

731

732

733

734

735

736

737

738

739

740

741

742

743

744

745

746

747

748

749

750

751

752

753

754

755

756

Figure 1. Quadrants of a Soybean Plant. The mature plant is divided up into quadrants upon harvest and each quadrant is analyzed separately. Plat normalized data uses the average of all four quadrants to normalize year, plot and line affects.

Figure 2. Canopy Gradients of Seed Composition Traits Before Normalization and Line and Year Effects on total accumulation. A) Composition gradients from the bottom to the top of the canopy for cultivar 'Chamberlain'. The plots display the quadrant average as a line with the 95\% confidence interval calculated using standard error as the ribbon. Units are $\mathrm{mg}$ (Single seed weight), PPM (Fe) and percentage for Protien and Oil) B) Year and line effects for each compositional trait, represented as boxplots. Units are PPM.

Figure 3. Canopy Gradients of Seed Composition Traits. For each trait, the data was normalized to the plot average to remove the effect of environment and genotype. The plots display the quadrant average as a line with the $95 \%$ confidence interval calculated using standard error as the ribbon. A) Percentage protein, percentage Oil and single seed weight. B) Elements with a significant $(p<1$ e -10$)$ effect of gradient in an ANOVA analysis that included Entry, Year and Position.

Figure 4. Correlation Plot among Composition Traits. Pearson correlation values between compositional traits. A) Correlation across 832 quadrants normalized to the plot average. B) Correlation across 208 plot means.

Figure 5. Effect of Thinning on Compositional Traits. For each trait, the data was normalized to the plot average to remove the effect of environment and genotype. The plots display the quadrant average as a line with the $95 \%$ confidence interval calculated using standard error as the ribbon. A) Percentage protein and percentage Oil in 2010. B) Elements (from 2010 and 2012) with a significant $(p<1$ e -10$)$ effect of gradient in an ANOVA analysis that included Entry, Year, Position and thinning.

757 
758 Figure 7. Canopy differences in Iron are reflected in food products. Fe content of the products 759 from 3 replicates of seven lines (flour) and four lines (Milk and Okara). Boxplots display the five 760 number summary (median, 25 , and $75 \%$ percentile define the box, with whiskers extending to $7611.5 \mathrm{x}$ interquartile range).

762 Figure 8. Canopy Gradients of Leaf Composition Traits. For each trait, the data was normalized 763 to the plot average to remove the effect of environment and genotype. The plots display the 764 quadrant average as a line with the $95 \%$ confidence interval calculated using standard error as 765 the ribbon. Elements with a significant $(\mathrm{p}<1 \mathrm{e}-10)$ effect of gradient in an ANOVA analysis 766 that included Entry, Collection Date and Position

767 Figure 9. Concentrations of selected primary metabolites in developing seeds of cultivar 768 'Williams 82'. A, Suc; B, citrate; and C, Asn. Boxplots display the five number summary 769 (median, 25, and 75\% percentile define the box, with whiskers extending to $1.5 \mathrm{x}$ interquartile 770 range) for three replicates at each sampling time: 7AM (7), 12N (12), 7PM (19) and the 771 following morning at 7AM (31). The black vertical bars represent the intervening night period. 772 Values are $\mu \mathrm{g}(\mathrm{g} \mathrm{DW})$.

773

774

775

Figure 10. Concentrations of free amino acids in developing seeds. Boxplots display the five number summary (median, 25 , and $75 \%$ percentile define the box, with whiskers extending to $1.5 \mathrm{x}$ interquartile range) for values from each sampling interval ( 3 replicates and 4 time points are merged within each box) and nodal position. Ornithine levels reflect both ornithine and arginine as arginine is converted to ornithine during sample prep for GC-MS. D1.bot, D1.top and D7.top refer to the samples collected on day one top and bottom quadrants and the day seven top quadrant respectively.

781

782

Supplemental File 1. Raw Gradient plots for each line/year combination. Values are PPM (Elements), mg (SampleWeight), and Percentage (Protein/Oil).

Supplemental File 2. All Compositional Traits Normalized Gradients.

786

787

Supplemental File 3. Interactive Correlation plots of all plot normalized data.

788

Supplemental File 4 . Interactive Correlation plots of plot mean data. 
791 Supplemental File 5. Interactive Correlation plots of all data, not normalized.

792

793 Supplemental File 6. Composition of Food products for all elements.

794

795 Supplemental File 7. Metabolomics analysis scheme.

796

797 Supplemental File 8. Global analysis of metabolome of developing soybean seeds. (A) PLS-DA 798 scores plot $\left(\mathrm{R}^{2}=98.7 \%, \mathrm{Q} 2=81.1 \%, P<0.001\right.$ by permutation test $)$ of soybean seeds at 799 different canopy position and time of day. (B) Variable Importance in the Projection (VIP) for 800 the first component showing the fifteen most important compounds.

801

802

Supplemental Table 1. Indeterminate lines used in the present study and selected characteristics

803

804

805

Supplemental Table 2. Weather summary (June 1-August 31) during the 2010 to 2012 growing seasons

806

807

808

Supplemental Table 3. Genotype differences in Seed fill period (SFP) and the difference in SFP

809

810

811

812

813

814

815

816 


\section{Figure 1}

Quadrants of a Soybean Plant.

The mature plant is divided up into quadrants upon harvest and each quadrant is analyzed separately. Plat normalized data uses the average of all four quadrants to normalize year, plot and line affects. 


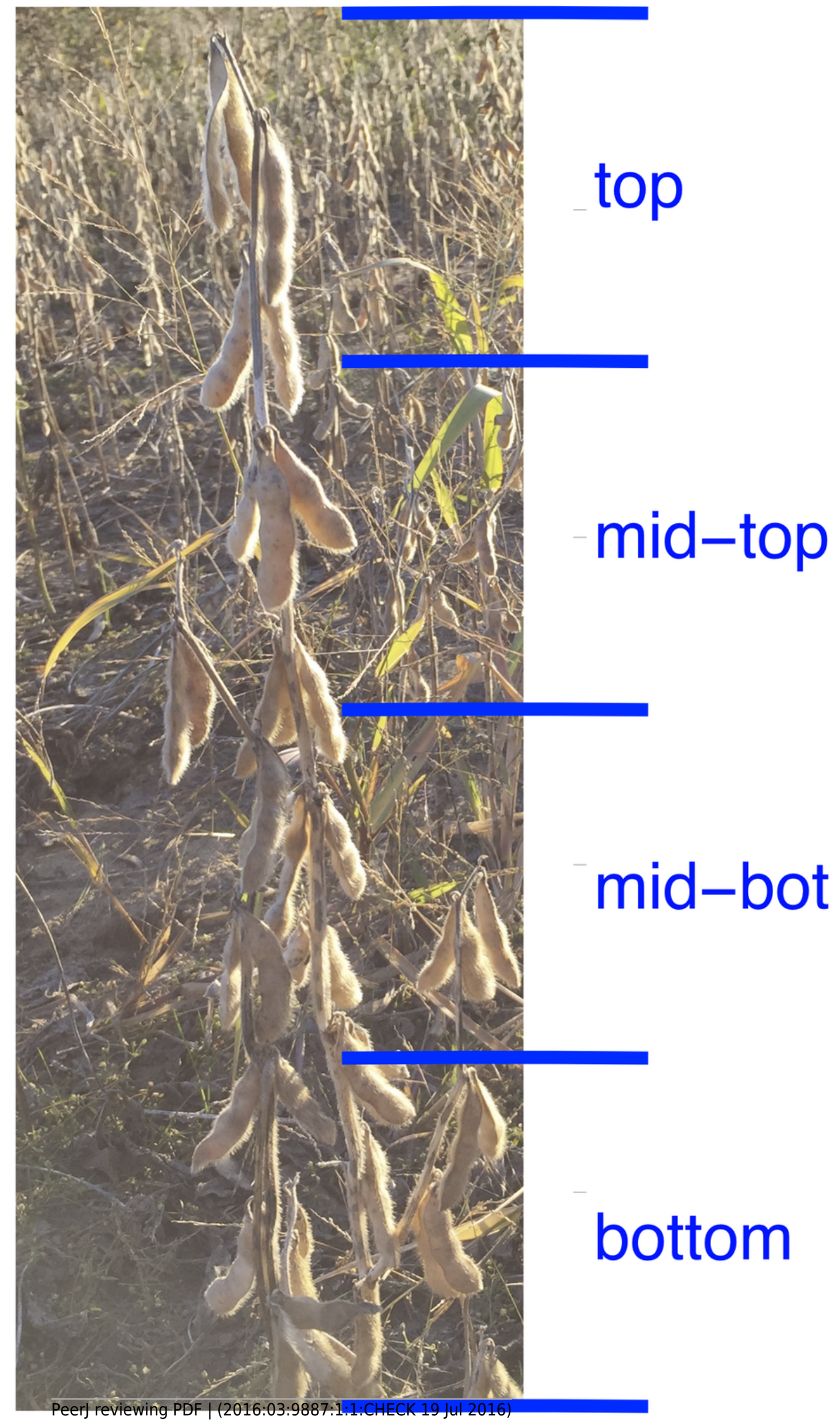


Figure 2

Canopy Gradients of Seed Composition Traits Before Normalization and Line and Year Effects on total accumulation.

A) Composition gradients from the bottom to the top of the canopy for cultivar 'Chamberlain'. The plots display the quadrant average as a line with the $95 \%$ confidence interval calculated using standard error as the ribbon. Units are mg (Single seed weight), PPM (Fe) and percentage for Protien and Oil) B) Year and line effects for each compositional trait, represented as boxplots. Units are PPM.
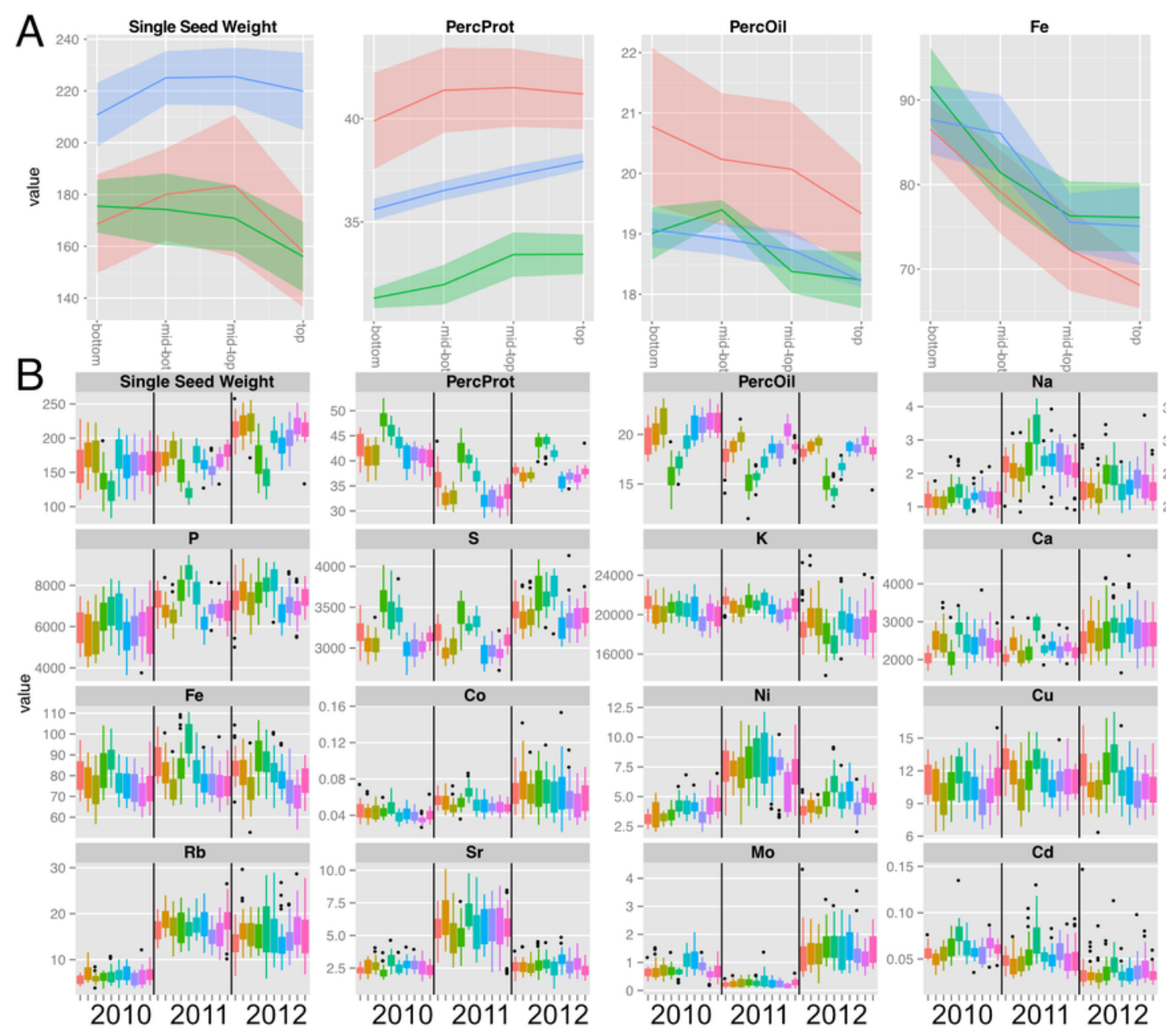

$-2010$

$-2011$

$-2012$

201020112012

201020112012

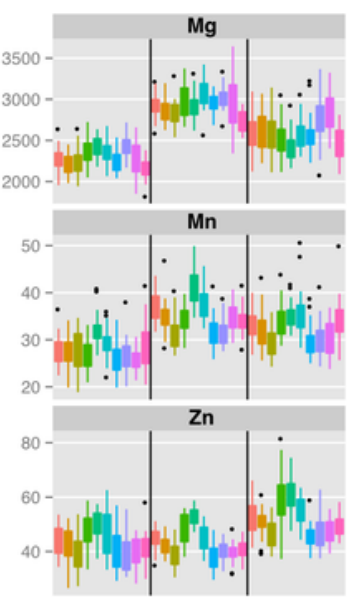

201020112012 Entry

Burlison LG00-15595

Chamberlain LG00-3372

Cumberland LN97-15076

LG00-13226

Logan

Williams 82 


\section{Figure 3}

Canopy Gradients of Seed Composition Traits.

For each trait, the data was normalized to the plot average to remove the effect of environment and genotype. The plots display the quadrant average as a line with the $95 \%$ confidence interval calculated using standard error as the ribbon. A) Percentage protein, percentage Oil and single seed weight. B) Elements with a significant $(p<1$ e -10) effect of gradient in an ANOVA analysis that included Entry, Year and Position. 

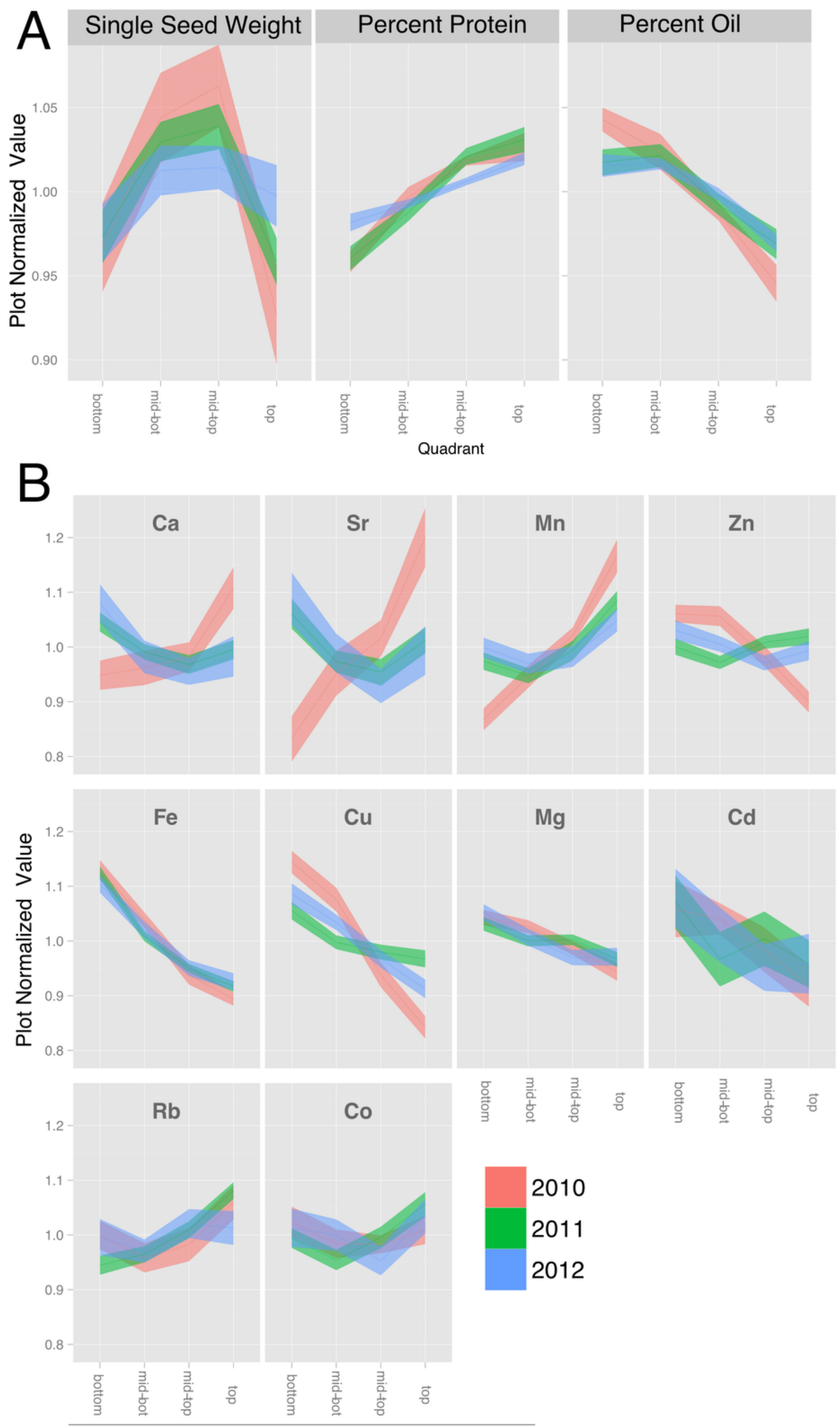


\section{Figure 4}

Correlation Plot among Composition Traits

Pearson correlation values between compositional traits. A) Correlation across 832 quadrants normalized to the plot average. B) Correlation across 208 plot means.

\section{A}

Plot Normalized Correlations

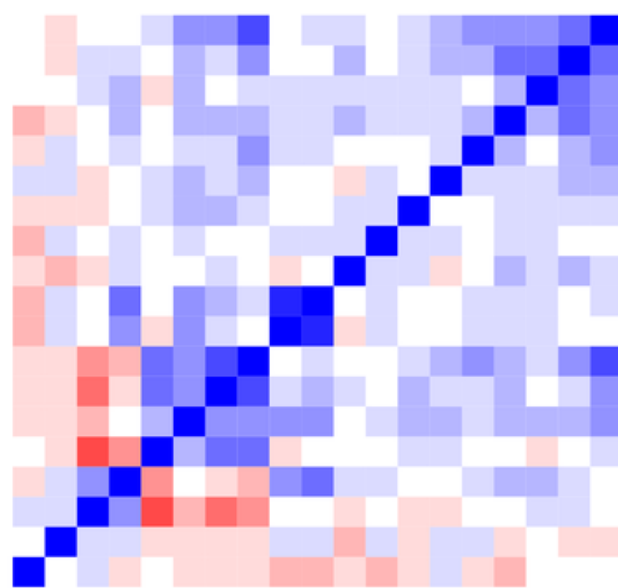

言赵 尊
B
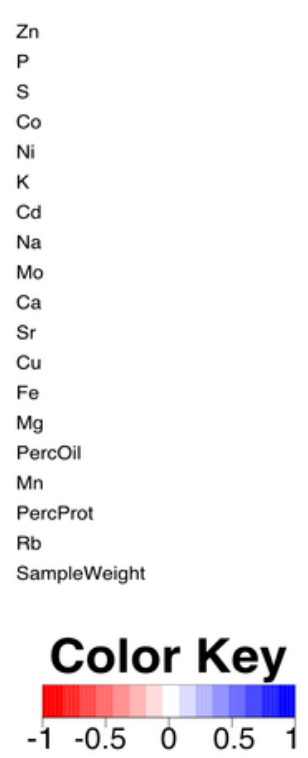

Plot Means-Correlations

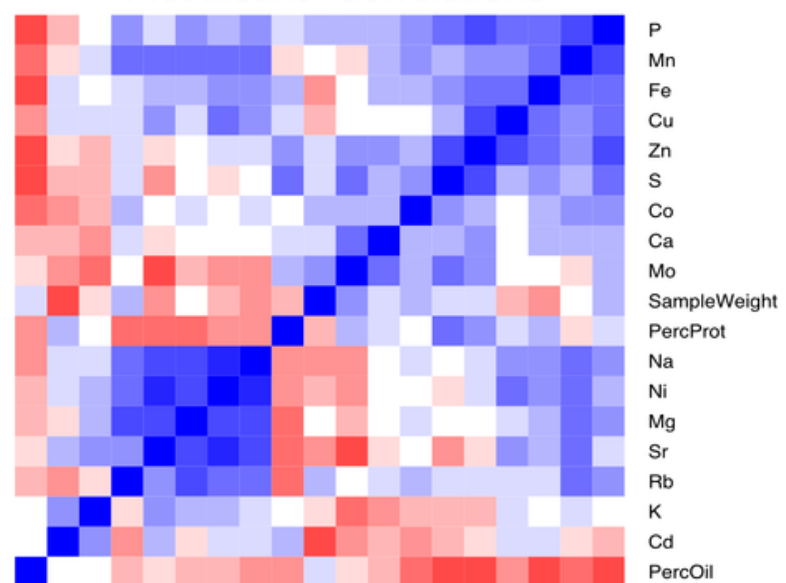
面 


\section{Figure 5}

\section{Effect of Thinning on Compositional Traits}

For each trait, the data was normalized to the plot average to remove the effect of environment and genotype. The plots display the quadrant average as a line with the $95 \%$ confidence interval calculated using standard error as the ribbon. A) Percentage protein and percentage Oil in 2010. B) Elements (from 2010 and 2012) with a significant ( $p<1$ e -10) effect of gradient in an ANOVA analysis that included Entry, Year, Position and thinning. 


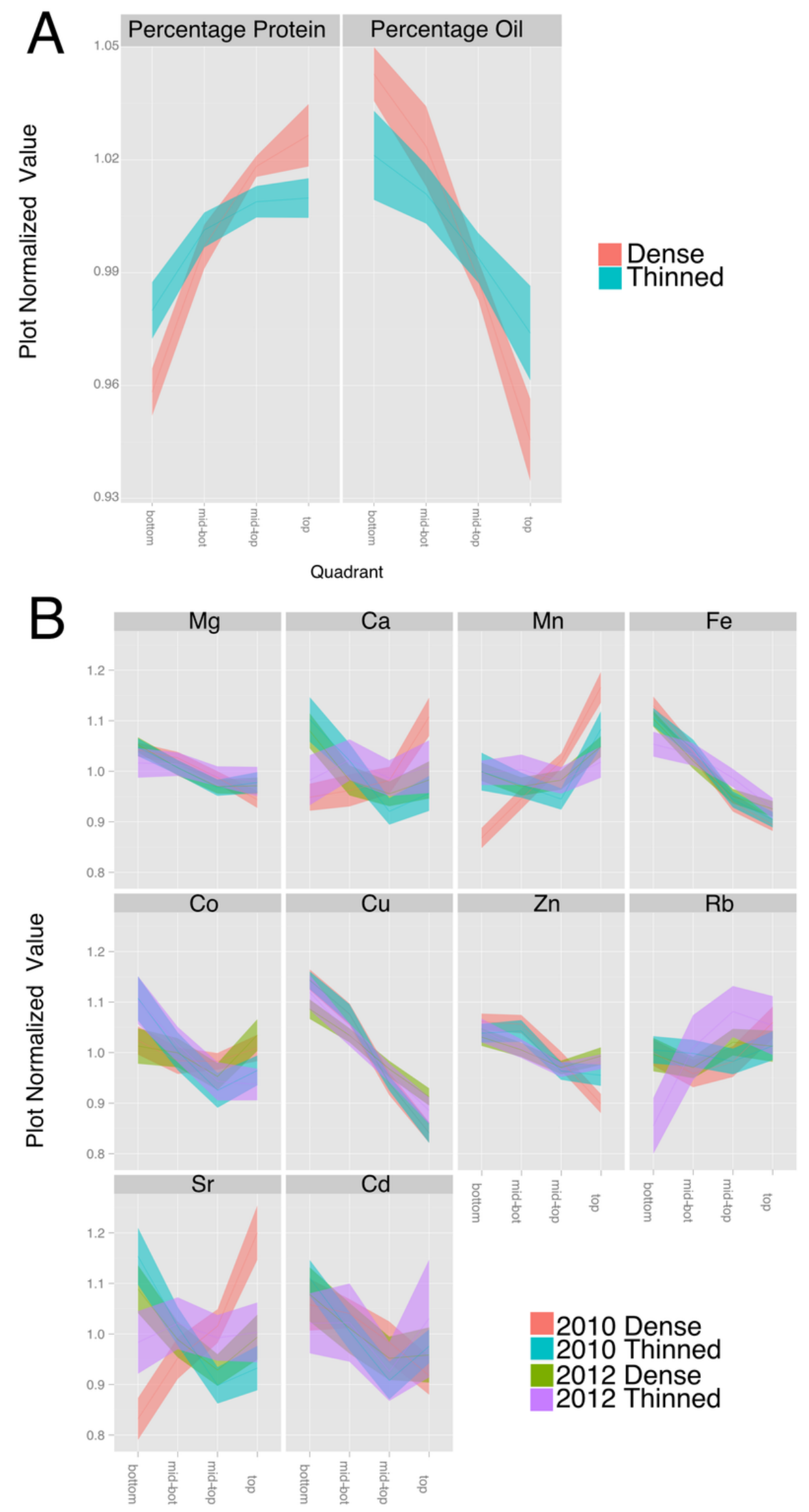


Figure 6

Difference in Top/Bottom composition traits is not correlated with Seed Fill Period

The difference in plot normalized composition between the top quad and the bottom quad for protein, oil and iron plotted versus the difference in seed fill period for 51 plots in 2012.

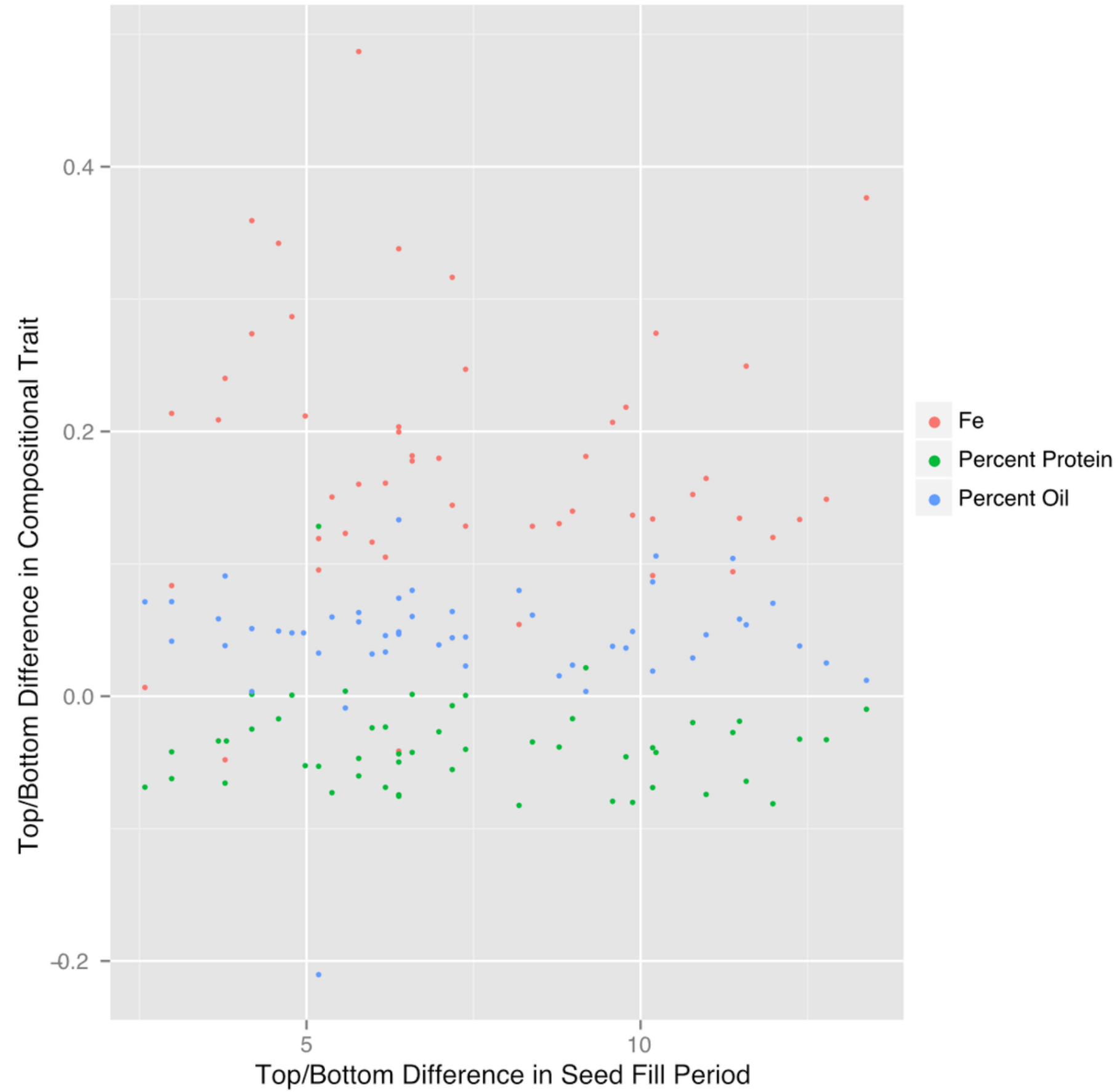




\section{Figure 7}

Canopy differences in Iron are reflected in food products.

Fe content of the products from 3 replicates of seven lines (flour) and four lines (Milk and Okara). Boxplots display the five number summary (median, 25 , and $75 \%$ percentile define the box, with whiskers extending to $1.5 \mathrm{x}$ interquartile range). 


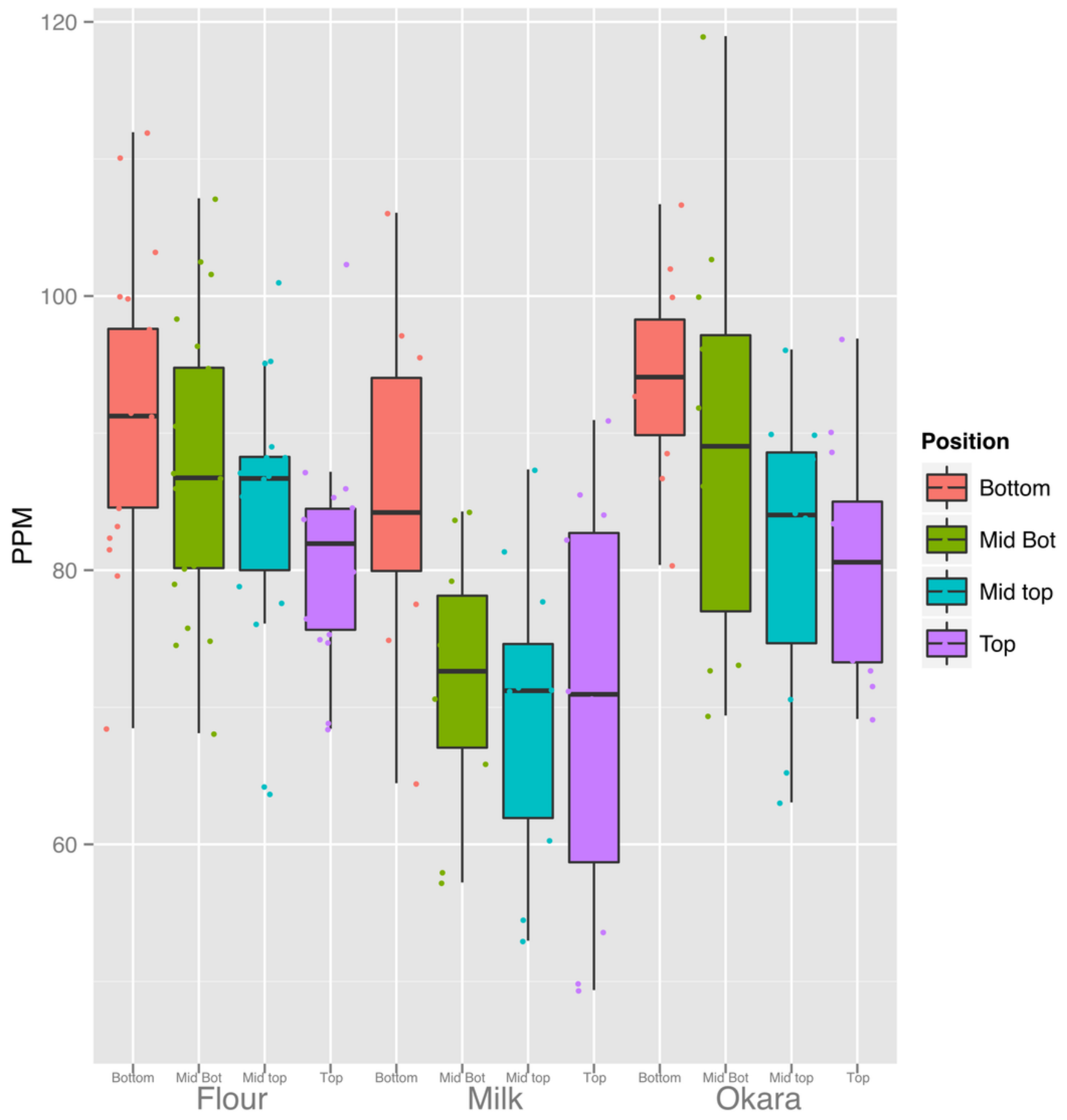




\section{Figure 8}

Canopy Gradients of Leaf Composition Traits

For each trait, the data was normalized to the plot average to remove the effect of environment and genotype. The plots display the quadrant average as a line with the $95 \%$ confidence interval calculated using standard error as the ribbon. Elements with a significant $(p<1$ e -10) effect of gradient in an ANOVA analysis that included Entry, Collection Date and Position 


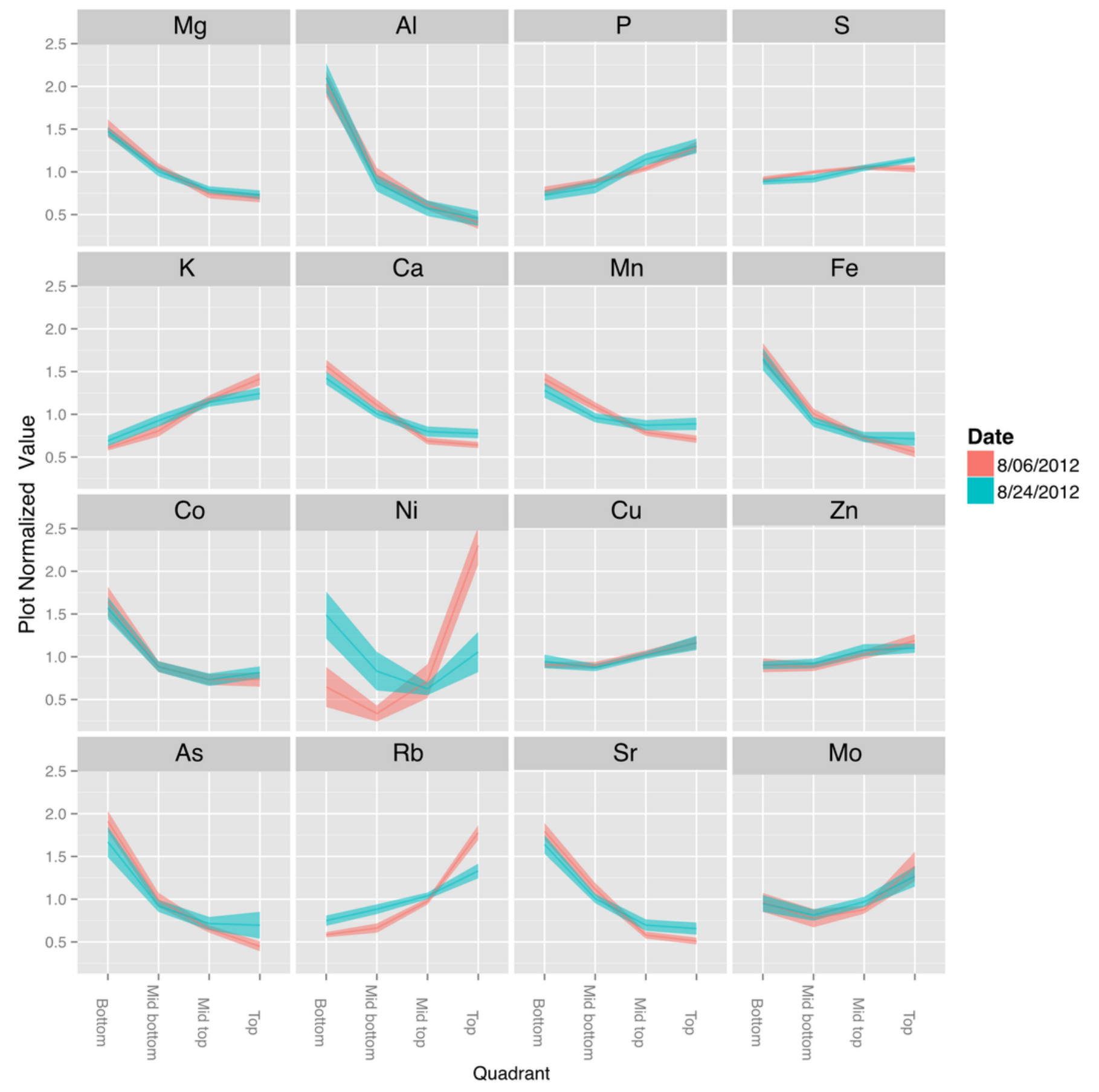


Figure 9

Concentrations of selected primary metabolites in developing seeds of cultivar 'Williams $82^{\prime}$

A, Suc; B, citrate; and C, Asn. Boxplots display the five number summary (median, 25, and $75 \%$ percentile define the box, with whiskers extending to $1.5 \mathrm{x}$ interquartile range) for three replicates at each sampling time: 7AM (7) , 12N (12) , 7PM (19) and the following morning at 7AM (31). The black vertical bars represent the intervening night period. Values are $\mu \mathrm{g}(\mathrm{g}$ DW). 

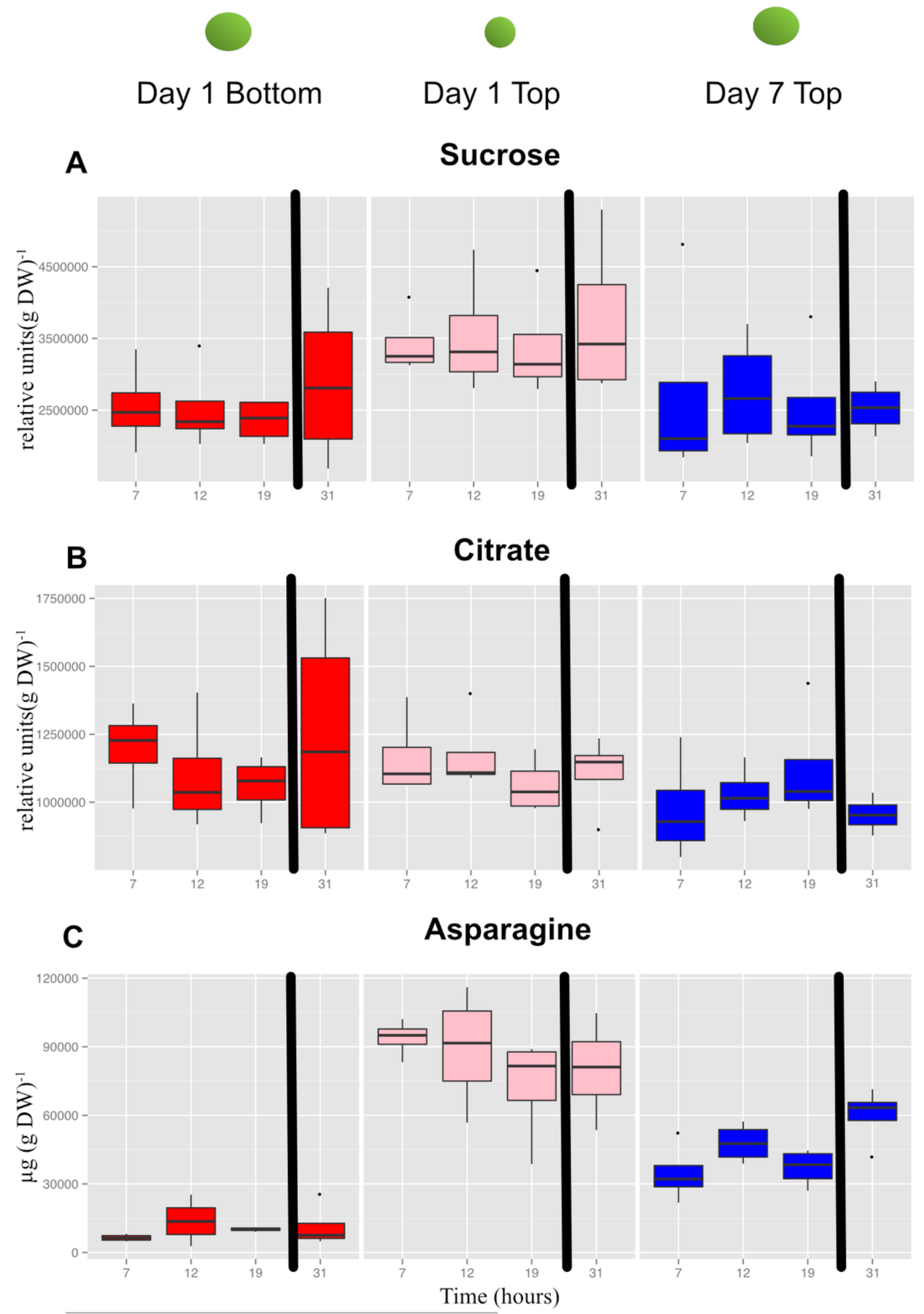


\section{Figure 10}

Concentrations of free amino acids in developing seeds

Boxplots display the five number summary (median, 25 , and $75 \%$ percentile define the box, with whiskers extending to $1.5 \mathrm{x}$ interquartile range) for values from each sampling interval ( 3 replicates and 4 time points are merged within each box) and nodal position. Ornithine levels reflect both ornithine and arginine as arginine is converted to ornithine during sample prep for GC-MS. D1.bot, D1.top and D7.top refer to the samples collected on day one top and bottom quadrants and the day seven top quadrant respectively.

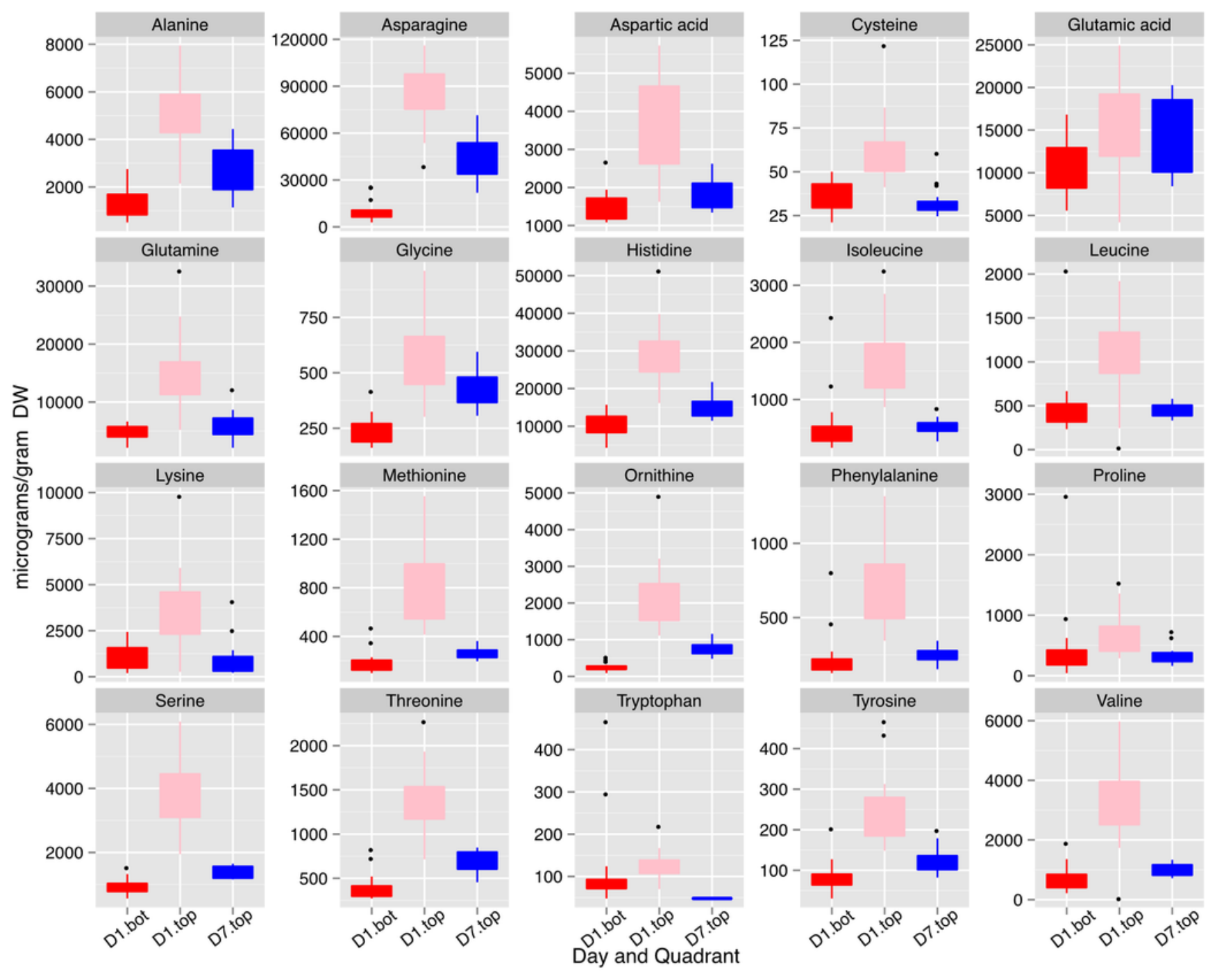

